University of Wollongong

Research Online

Faculty of Engineering and Information

Faculty of Engineering and Information

Sciences - Papers: Part A

Sciences

January 2016

\title{
Removal of emerging contaminants for water reuse by membrane technology
}

\section{Long D. Nghiem}

University of Wollongong, longn@uow.edu.au

Takahiro Fujioka

Nagasaki University, takahiro@uow.edu.au

Follow this and additional works at: https://ro.uow.edu.au/eispapers

Research Online is the open access institutional repository for the University of Wollongong. For further information contact the UOW Library: research-pubs@uow.edu.au 


\title{
Removal of emerging contaminants for water reuse by membrane technology
}

\begin{abstract}
Emerging trace organic contaminants (TrOCs) are broadly defined as any synthetic or naturally occurring chemicals that have not been routinely monitored but have the potential to enter the environment and cause known or suspected adverse ecological or human health effects [1]. Most of these TrOCs are from municipal, agricultural and industrial wastewater sources (see Figure 9.1). Their release to the environment had likely occurred for a long time but was only recently recognised by new and advanced analytical methods [2]. In some cases, emerging contaminants can also result from the synthesis of new chemicals either intentionally as a chemical of industrial interest or unintentionally as a by-product. A notable example of the latter is the $\mathrm{N}$-nitrosamine group that can be formed as by-products due to a range of industrial activities including the production of rocket fuel, rubber and tobacco as well as water or wastewater disinfection by chloramine [3].
\end{abstract}

\section{Keywords}

emerging, membrane, removal, water, reuse, contaminants, technology

\section{Publication Details}

Nghiem, L. D. \& Fujioka, T. (2016). Removal of emerging contaminants for water reuse by membrane technology. In N. P. Hankins \& R. Singh (Eds.), Emerging Membrane Technology for Sustainable Water Treatment (pp. 217-247). Amsterdam, Netherlands: Elsevier. 


\title{
The Removal of Emerging Contaminants for Water Reuse by Membrane Technology
}

\author{
Long D. Nghiem ${ }^{1}$ and Takahiro Fujioka ${ }^{2}$ \\ ${ }^{1}$ Strategic Water Infrastructure Laboratory, School of Civil Mining and Environmental \\ Engineering, University of Wollongong, Wollongong, NSW 2522, Australia \\ ${ }^{2}$ Water and Environmental Engineering, Graduate School of Engineering, \\ Nagasaki University, Nagasaki, Japan
}

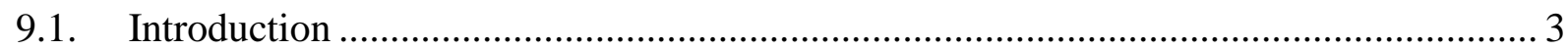

9.2. Membrane technology for water reclamation .......................................................... 4

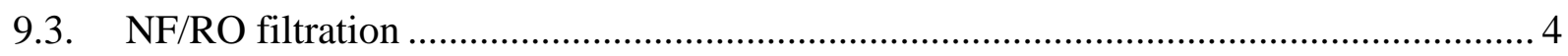

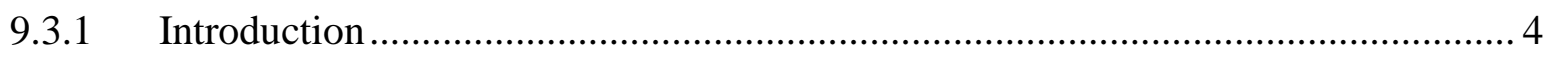

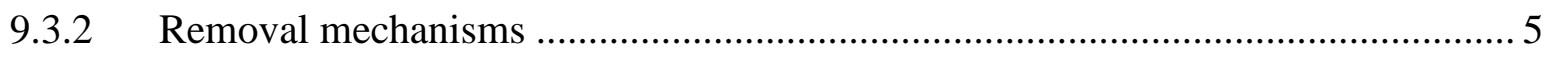

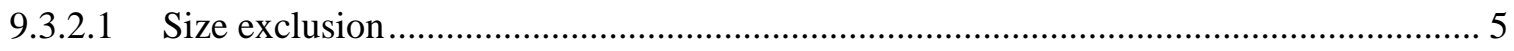

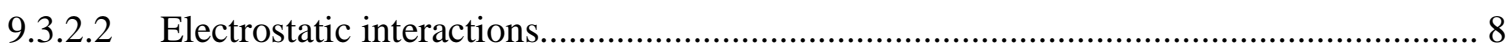

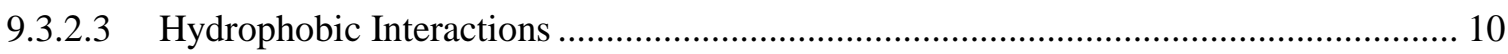

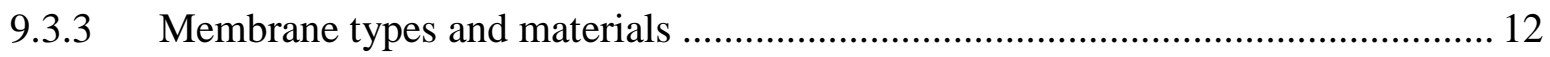

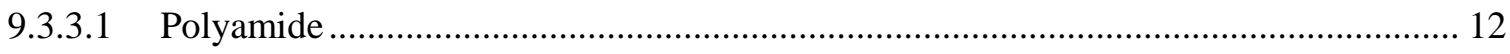

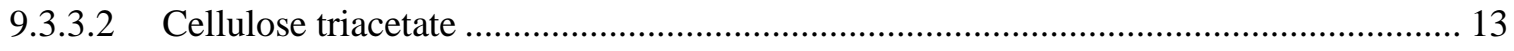

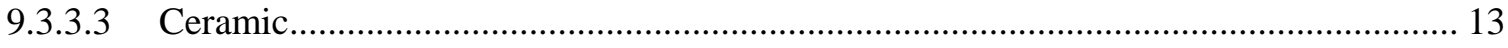

9.3.4 Effects of membrane fouling and chemical cleaning.......................................... 14

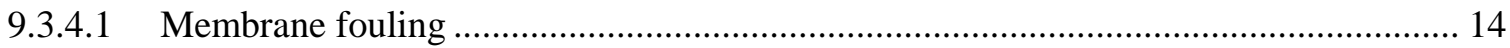

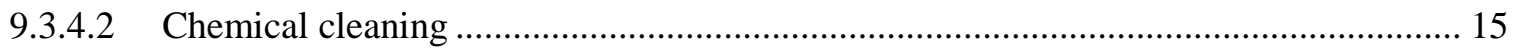

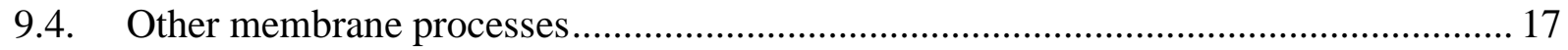

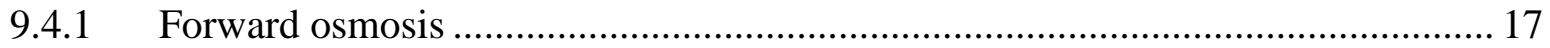

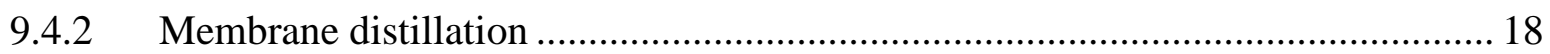

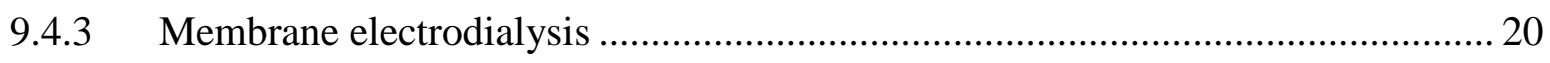

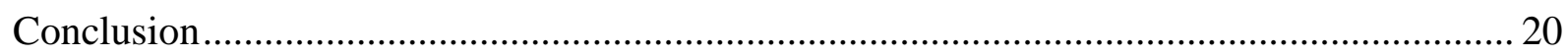

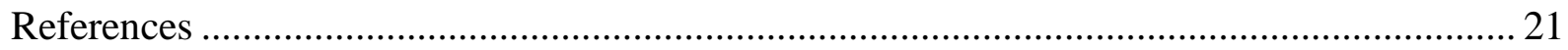




\begin{abstract}
High pressure membrane filtration processes including both reverse osmosis (RO) and nanofiltration (NF) have been widely used in drinking purification and water recycling, particularly for the removal of trace organic contaminants (TrOCs). It is therefore essential to understand the transport of TrOCs through NF/RO membranes ensure adequate treatment and at the same time avoid over-engineering. TrOC rejection by NF/RO membranes is governed mainly by size exclusion, electrostatic repulsion, and hydrophobic interaction. A detailed characterisation of the membrane and physicochemical properties of the TrOC is a key to recognising the dominant mechanism. TrOC rejection by NF/RO membranes can also be influenced by fouling and subsequent chemical cleaning. In addition to NF/RO membranes, TrOC removal by several emerging membrane technologies including forward osmosis, membrane distillation and membrane electrodialysis was also briefly reviewed.
\end{abstract}

Keyword: drinking water; nanofiltration; reverse osmosis; trace organic contaminants; water recycling. 


\subsection{Introduction}

In this chapter, emerging trace organic contaminants (TrOCs) are broadly defined as any synthetic or naturally occurring chemical that has not been routinely monitored but has the potential to enter the environment and cause known or suspected adverse ecological or human health effects [1]. Most of these TrOCs are from municipal, agricultural, and industrial wastewater sources and pathways (Figure 9.1). Their release to the environment had likely occurred for a long time but was only recently recognized by new and advanced detection methods [2]. In some cases, emerging contaminants can also arrive from the synthesis of new chemical either intentionally as a chemical of industrial interest or unintentionally as a byproduct. A notable example is the n-Nitrosamine group that is can be formed as by-products in a range of industrial activities (e.g. the production of rocket fuel, rubber, and tobacco) and water or wastewater disinfection using chloramine [3].

\section{[Figure 9.1]}

TrOCs can be classified into a number of groups depending on their origin, use, or properties. These include, but not limited to, steroid hormones, phytoestrogens, endocrine disrupting chemicals, pharmaceuticals and personal care products, industrial chemicals, disinfection byproducts, and pesticides. There is considerable overlap amongst these groups as they are often loosely defined. In most cases, TrOCs are ubiquitous in reclaimed water at concentrations in the range from less than one part-per-trillion $(\mathrm{ng} / \mathrm{L})$ to a few part-per-billion $(\mu \mathrm{g} / \mathrm{L})$. At their environmental concentrations, some of these TrOCs pose toxicological threats to wildlife and potential long-term adverse human health effects. They can only be detectable by some of the most advanced analytical techniques [2]. The difficulties associated with their analysis and accurately evaluating their impact on human health present a major scientific challenge in addressing water quality problems caused by these TrOCs.

Regulatory response to the widespread occurrence of thousands of these emerging contaminants in both drinking and natural water varies quite significantly. Given the lack of affordable techniques for routinely monitoring, only some of these emerging contaminants have been regulated in drinking water. For example, in Australia, the guideline value of nNitrosodimethylamine (NDMA), which is a carcinogenic disinfection by-product, in drinking water is specified at $100 \mathrm{ng} / \mathrm{L}$ or less [4]. On the other hand, more than a hundred of these emerging contaminants have been included in water recycling (or reuse) guideline for drinking water augmentation [5]. It is also noteworthy that the guideline value for water 
recycling is often more stringent than that for drinking water. This is to reflect the ubiquitous occurrence of some emerging contaminants (e.g. pharmaceuticals and steroid hormones) in municipal wastewater. As an example, Table 9.1 illustrates the variation in guideline values of NDMA and several other n-nitrosamines amongst several different regulatory agencies [4-9].

\section{[Table 9.1]}

\subsection{Membrane technology for water reclamation}

Conventional wastewater treatment processes include activated sludge treatment, coagulation/flocculation, and sand filtration were not designed for the removal of emerging contaminants and thus were largely ineffective. As a result, the industry relies must rely on a range of advanced treatment processes such as ozonation, advanced oxidation, activated carbon adsorption and membrane separation. In particular, high pressure membrane processes including both nanofiltration (NF) and reverse osmosis (RO), have been widely deployed for the removal of emerging contaminants. Indeed, most recent full scale NF or RO installations are for drinking water production from contaminated surface water and potable water recycling applications specifically for removing emerging contaminants $[3,10,11]$ (Table 9.2). Other noteworthy membrane processes that have the potential for removing emerging trace organic contaminants but have yet been applied at full scale level include forward osmosis (FO), membrane distillation (MD), and membrane electrodialysis (ED). Given their still emerging nature, this chapter will not provide an exhaustive review about FO, MD, and ED. Instead, only key aspects associated with the removal of emerging trace organic contaminants will be discussed.

\section{[Table 9.2]}

\subsection{NF/RO filtration}

\subsubsection{Introduction}

High pressure membrane filtration is capable of removing most impurities from water. Over recent decades, technological advances in the production of materials and modules have reduced the costs of water treatment systems using high pressure membrane processes including both RO and NF. RO and NF membranes are differentiated by their ability to separate mono- and di-valent ions. For example, RO membranes are typically used for 
seawater desalination, wastewater recycling and in the semiconductor industry where a high removal of salts and other dissolved contaminants, including TrOCs, is required. On the other hand, NF membranes have been used in drinking water treatment plants where the source (e.g. ground or surface water) contains divalent ions (e.g. calcium and manganese) that are of significant concern or has been compromised with TrOCs. However, uncertainty associated with the removal of TrOCs by NF/RO membranes has triggered the need for additional posttreatment or blending with pristine water. As a result, many studies have focused on the mechanisms for TrOC removal in NF/RO filtration, as understanding these mechanisms can improve membrane system design and the quality of product water. This section focuses on the theories describing the transport of TrOCs in NF/RO systems which have developed over the past decade.

\subsubsection{Removal mechanisms}

Transport through NF/RO membranes is often described by the solution-diffusion model in which solutes diffuse through the membrane from the feed side to the permeate side, leading to a concentration gradient across the membrane. In diffusion-governed separation processes, the separation depends on the mobility of the diffusing species in the membrane polymer chains and the local environment at the membrane surface. There are many different TrOCs and commercial NF/RO membranes, all of which have different physicochemical properties, and the reported rejection depends on both the TrOC considered and the membrane. Hence, correlation of TrOC rejections with the physicochemical properties of these compounds and the properties of the membrane is key to providing comprehensive guidance on TrOC removal in NF/RO systems, and has been extensively researched using both experimental and theoretical studies. The mutual interaction between TrOCs and membranes are essentially divided into three broad categories - size, electrostatic, and hydrophobic interactions - all of which are described in this section.

\subsubsection{Size exclusion}

Size exclusion plays a primarily role in the separation of TrOCs using NF/RO membranes. The effect of compound size is particularly noticeable when the rejection of neutral TrOCs are compared [12]. Separation by size exclusion occurs by a sieving mechanism, in which large TrOCs are blocked and smaller TrOCs readily diffuse through the membrane. In other words, the level of rejection of a TrOC is determined by the difference in size of the TrOC and the free-volume (between polymer chains) of the active skin layer of the membrane. Hence, 
characterisation of the relative sizes of TrOCs and membrane free-volumes is essential to understanding how size interactions influence TrOC rejection by NF/RO membranes.

\subsection{Molecular size}

The molecular size of TrOCs can be expressed by a variety of terms. The evaluation of TrOC rejection by NF/RO membranes is commonly performed with the molecular weight (MW) [13, 14]. Typically, the rejection of TrOCs by a given membrane increases with their molecular weight due to the sieving effect. Despite its enormous popularity in the field, the MW does not provide any information on the TrOC geometry and cannot be used to accurately predict TrOC rejection. Indeed, TrOCs with similar MWs can have vastly geometries (e.g. length and width). Other terms used to describe molecular size, such as molecular volume and stokes radius, also fail to provide information on the compound geometry and cannot be used to accurately predict TrOC rejection.

The transport of TrOCs through NF/RO membranes can be better described by the molecular width (MWd). The term MWd was first proposed by Kiso et al. [15] to describe the projected two-dimensional area of a molecule, and it is critical to understanding the passage of compounds through the free-volume holes of a membrane. As illustrated in Figure 9.2, the MWd is calculated from the area $(S)$ of the minimum rectangle area perpendicular to the Laxis (the line connecting the two most distant atoms of the molecule) [16]. A more detailed description of MWd is given elsewhere [16]. In fact, the minimum projection area (MPA) and its derivative property - MWd - of neutral TrOCs are strongly correlated with their rejection by a given membrane [16-18]. However, these correlations are limited to hydrophilic neutral TrOCs. Strongly hydrophobic compounds (e.g. bisphenol A, $\log D=4.0$ ) are poorly rejected [17] which impacts the correlation between the minimum projection area of TrOCs and their rejection (Figure 9.3). Hence the removal mechanism responsible for the observed rejection of neutral TrOCs cannot be explained by the molecular size alone. The impact of hydrophobic interactions on TrOC rejection will be discussed in a later section.

\section{[Figure 9.2]}

\section{[Figure 9.3]}

\subsection{Free-volume hole}

Internal structure of active skin layer of NF/RO membranes have not been adequately characterised at the relevant sub-nanometre scale level. Thus, an accurate description of the 
transport of small solutes through NF/RO membranes based on the molecular size and membrane properties has yet been developed. Unlike microfiltration (MF) and ultrafiltration (UF) membranes, where separation occurs by sieving through micro-pores that can be accurately visualised and measured, it is widely accepted that free-volume holes exist in the active skin layer of NF/RO membranes.

The separation performance of NF membranes has been traditionally described with the term, molecular weight cut-off (MWCO). MWCO is defined as the molecular weight of a compound that is $90 \%$ rejected by the membrane. MWCOs of typical NF membranes normally range from 200 to $1000 \mathrm{~g} / \mathrm{mol}$. While the transition between NF and RO membranes seems to be in the range $100-200 \mathrm{~g} / \mathrm{mol}$, it is not common to specify RO membranes using the MWCO. As the MWCO is an experimentally measured value, it reflects the effect of multiple rejection mechanisms including size and hydrophobic interactions. Moreover, MWCO does not provide any information about the dimensions (e.g. length and width) of a free-volume hole. As a result, the MWCO alone does not provide sufficient information on the rejection of different sized molecules by a NF membrane. In fact, the ability of MWCO to predict the rejection of a TrOC by a NF membrane is often limited [19].

It is evident that free-volume hole size is a more appropriate term than MWCO to evaluate the size exclusion removal mechanism. Recently, advances in positron annihilation lifetime spectroscopy (PALS) [20-22] have enabled the measurement of mean free-volume hole size in the active skin layer of NF/RO membranes [23, 24]. The size of free-volume holes is determined using the lifetime of positrons discharged into the membrane sample at a different depths in the skin layer. The reported free-volume hole radii of seawater RO, low pressure RO, and NF membranes are comparable at 0.26-0.28, 0.20-0.29, and 0.26-0.28 nm, respectively. Despite this, the reported rejection of a neutral solute, n-Nitrosodimethylamine, ranges from $4-78 \%$ for these membranes [25]. In fact for a variety of RO membranes, the rejection of a neutral solute did not correlate with the membrane free-volume hole-size (analysed using PALS) except when the membranes were produced using the same manufacturing method and similar materials [24, 26]. As a result, the size exclusion mechanism cannot solely be described by the free-volume hole size. Other properties that may influence the diffusion of neutral solutes through a membrane include the shape and size distribution of free-volume holes. In addition, other membrane properties such as the free-volume fraction and thickness of the active skin layer could alter the diffusion of solutes though the membrane. A more detailed discussion on these membrane properties is provided elsewhere [25]. 


\subsubsection{Electrostatic interactions}

The second key factor influencing the rejection of TrOCs by NF/RO membranes is electrostatic interactions. Electrostatic interactions are characterised by the electrostatic repulsion or attraction between two charged objects - a charged compound and membrane. Membrane surfaces are typically negatively charged and negatively charged TrOCs are repelled by the membrane, resulting in a higher rejection these compounds. In contrast, positively charged TrOCs are essentially attracted to the membrane, which results in a lower rejection of these compounds. Uncharged TrOCs are not subject to electrostatic interactions with the membrane. Consequently, it is important to attain information regarding the charge of both TrOCs and NF/RO membranes during system operation.

\subsection{Molecular charge}

Most ionisable compounds can be classified as either negatively or positively charged. A compound that contains both negatively and positively charged functional groups at a specific $\mathrm{pH}$ is called zwitterion. The compound charge of ionisable TrOCs depends on the ionisation sate of its ionisable functional groups. For example, a carboxyl group $(\mathrm{COOH})$ on a compound acts as an acid when present in its dissociated form ( $\left.\mathrm{COO}^{-}\right)$. Similarly, an amine group $\left(\mathrm{NH}_{2}\right)$ in its protonated form $\left(\mathrm{NH}_{3}{ }^{+}\right)$acts as a base. The degree of dissociation of a compound can be estimated using the acidity constant $(\mathrm{Ka})$ or base constant $(\mathrm{Kb})$. These constants are generally expressed as $\mathrm{pKa}$ and $\mathrm{pKb}$, and are defined as a negative logarithm of equilibrium constants $\mathrm{Ka}$ and $\mathrm{Kb}$, respectively. $\mathrm{pKa}$ is defined as the $\mathrm{pH}$ at which a compound exists $50 \%$ in its dissociated form. As a result, there is a range of $\mathrm{pH}$ around the $\mathrm{pKa}$ and $\mathrm{pKb}$ at which both dissociated and neutral species coexist. It is also important to note that the pKa and $\mathrm{pKb}$ values depend on the solution temperature.

The speciation of two ionisable TrOCs over a wide $\mathrm{pH}$ range is presented in Figure 9.4 for illustration purposes. Ibuprofen, which contains a $\mathrm{COOH}$ group on its molecular structure, is not charged at low solution $\mathrm{pH}$ (pH 3 or lower) (Figure 9.4a). However, as the solution $\mathrm{pH}$ increases from 3 to 7 , the $\mathrm{COOH}$ group begins to dissociate and almost all ibuprofen molecules are negatively charged at when the solution $\mathrm{pH}$ is above 7 . Amitriptyline $(\mathrm{pKb}=$ 9.8) is positively charged at low solution $\mathrm{pH}(\mathrm{pH} \leq 8)$ and mostly becomes neutral at high solution $\mathrm{pH}(\mathrm{pH} \geq 12$ ) (Figure 9.4b). In drinking and municipal wastewater applications, the $\mathrm{pH}$ of the feed to the NF/RO is typically adjusted to between 6 and 8; thus, the speciation of compounds over this range is of considerable importance. 


\section{[Figure 9.4]}

\subsection{Membrane charge}

NF/RO membranes are commercially produced from several different materials. To determine the charge interaction between the membrane and charged TrOCs, it is important to know the charge of a given membrane over a $\mathrm{pH}$ range (e.g. $\mathrm{pH} 3$ to 10). The material used for the active layer of NF/RO membranes is usually a polyamide derivative, sulphonated polyethersulphone, cellulose acetate or titanium-based ceramic. Many water recycling and seawater desalination plants employ thin film composite NF/RO membranes with a polyamide active separation layer. Thus, a special focus is placed on polyamide-based NF/RO membranes in this section.

The surface charge of membranes (including MF, UF, NF and RO) is typically determined by the zeta potential. The active skin layer of commercial polyamide NF/RO membranes contains ionisable functional groups such as carboxyl $(\mathrm{COOH})$ and sulfonic $(\mathrm{SOH})$ groups. These functional groups are dissociated and negatively charged at high $\mathrm{pH}$; thus, the zeta potential of polyamide NF/RO membranes decreases with the solution $\mathrm{pH}$ (Figure 9.5). It is important to note that the measured charge varies as a function of the variety and concentration of background electrolytes (e.g. $\mathrm{KCl}$ ).

Over the typical $\mathrm{pH}$ range for $\mathrm{NF} / \mathrm{RO}$ feeds (i.e. $\mathrm{pH}$ 6-8), the surface charge of commercial $\mathrm{NF} / \mathrm{RO}$ membranes is typically negative due to deprotonated functional groups (e.g. sulfonic acid and carboxylic acid) of the active skin layer. A list of typical NF/RO membranes and their zeta potentials is presented in Table 9.3 [27]. Recently, NF and RO membranes with a weak negative charge have been developed to reduce membrane fouling by minimising the charge interactions between the membrane and charged organic matter. Both LFC3 (RO) and ESNA-LF (NF), which are supplied by Hydranautics, are reported to have a weak negative charge [28]. However, since the negative charge of these membranes is weaker than typical NF/RO membranes, the charge interactions between the membrane and charged TrOCs may also be hindered.

[Figure 9.5]

[Table 9.3] 


\subsection{Effect of electrostatic interactions}

A series of experimental results illustrating the effect of charge interactions is presented in Figure 9.6. The NF270 membrane used in the work carries a negative surface charge at pH 8. No apparent difference was found in the rejection of charged and uncharged TrOCs for large compounds (MPA >60 $\AA$ ). However, the effects of electrostatic repulsion became noticeable when the MPA dropped below $50 \AA$. The rejection of negatively charged compounds was generally higher (approximately $>90 \%$ ), with exception of triclosan (MPA $=39 \AA$ ). Of the TrOCs studied, Triclosan is the most hydrophobic compound ( $\log D=4.57$ ) and therefore subject to hydrophobic interactions. Hydrophobic interactions are described in the following section. The enhanced rejection of negatively charged compounds is driven by the electrostatic repulsion force between the membrane and charged compounds. Although the compound size still influences the permeation of the negatively charged TrOCs through the NF270 membrane, the relationship between rejection and MPA does not follow the same trend as neutral TrOCs (Figure 9.6). In contrast, the rejection of positively charged TrOCs was generally lower than negatively charged TrOCs. This is due to electrostatic attraction between the positively charged compounds and the negatively charged membrane. The attracted compounds are concentrated at the membrane surface while negatively charged compounds remain in the bulk solution, resulting in a lower measured rejection of positively charged compounds compared to their negatively charged counterparts [29]. This phenomenon is commonly called charge concentration polarisation [30].

\section{[Figure 9.6]}

\subsubsection{Hydrophobic Interactions}

Hydrophobic interactions between nonpolar (hydrophobic) TrOCs and hydrophobic NF/RO membranes can influence the separation of these compounds. Hydrophobic substances, including hydrophobic TrOCs, do not mix well with water but adsorb onto other hydrophobic materials such as membranes. The adsorbed compound is concentrated at the membrane surface, resulting in a lower measured rejection. Consequently, hydrophobic interactions need to be considered when evaluating the rejection of hydrophobic TrOCs by NF/RO membranes.

\subsection{Molecular hydrophobicity}

The hydrophobicity of TrOCs is typically quantified using the octanol/water partitioning coefficient (Log Kow) or effective octanol/water partitioning coefficient (Log D). Log Kow is defined as the ratio of the concentration of unionised compounds in the octanol phase to the 
concentration in the water phase. Log Kow is generally used for neutral (uncharged) compounds. On the other hand, $\log D$ takes into account the ratio between the ionised over unionised form of the compound at a specific $\mathrm{pH}$ value. Therefore, the hydrophobicity of ionisable compounds, as determined by the $\log D$, is specific to the solution $\mathrm{pH}$. For a nonionisable compound $\log D$ and $\log D$ are the same. In NF/RO systems, the transition of compounds from hydrophobic to hydrophilic typically occurs at a $\log D$ (or Log Kow) value in between 2 and 3 [12,31]. Consequently, TrOCs with a Log $D$ above 3 are classified as hydrophobic and may adsorb on the membrane surface due to hydrophobic interactions. In contrast, hydrophilic compounds ( $\log D<2$ ) are not subject to hydrophobic interactions with the membrane.

\subsection{Membrane hydrophobicity}

The hydrophobicity of a NF/RO membrane surface is evaluated experimentally by measuring the contact angle. The contact angle is defined as the angle between the solid surface (membrane) and the liquid (water) droplet, and is measured using a goniometer. The contact angle of $\mathrm{NF} / \mathrm{RO}$ membrane surfaces ranges from 20 to $50^{\circ}$ [27]. It is worth mentioning that the surface hydrophobicity can change over long-term system operation due to fouling and chemical cleaning. While the surface contact angle describes the hydrophobicity of membrane surfaces well, no techniques have been established to directly measure the hydrophobicity of the free-volume hole walls of the active skin layer (though this is where TrOCs diffuse through). Unlike for TrOCs, there are no clear quantitative criteria for distinguishing hydrophobic and hydrophilic membranes based on the measured contract angle. Rather, membranes are qualitatively described as more or less hydrophobic based on their observed potential for hydrophobic interactions. All commercial NF/RO membranes are generally considered hydrophobic, regardless of their measured contact angle.

\subsection{Impact of hydrophobic interactions}

TrOCs adsorb onto a membrane surface as a result of hydrophobic interactions, though this is a slow process in NF/RO filtration. The effect of hydrophobic interactions can be clearly identified in experiments using a closed loop filtration system, commonly employed for laboratory-scale evaluations. As a result of adsorption, the concentration of a compound at the membrane surface becomes higher than the concentration in the bulk feed solution. The increased concentration at the surface allows more compounds to permeate through the membrane, thereby lowering the compound rejection. As described earlier, the adsorption of 
compounds onto the membrane by the hydrophobic interaction mostly occurs for hydrophobic compounds ( $\log D>2$ ). The adsorption effect may become more noticeable for strongly hydrophobic compounds, for example bisphenol A $(\log D=4.0)$ as shown in Figure 9.3.

Due to the effect of adsorption, the feed concentration of a compound will gradually decrease while the permeate concentration will increase during operation of a closed loop system. Depending on the membrane and compound considered, this phenomenon may continue for several hours to days as presented in Figure 9.7 [32]. Evaluating the rejection of TrOCs before a steady state is obtained can lead to an overestimation of the membrane separation performance. It is also important to note that strongly hydrophobic compounds may be depleted over time in a closed filtration system due to adsorption, which prevents evaluation of their rejection. The potential overestimation of rejection is almost negligible in full-scale NF/RO filtration systems that have been operated at steady state for months.

\section{[Figure 9.7]}

\subsubsection{Membrane types and materials}

\subsubsection{Polyamide}

Interfacial thin-film composite (TFC) RO membranes became the industry standard in the 1970s [33, 34], and have been widely used in a variety of water treatment applications ever since. The membranes are produced in a flat sheet style and are supplied in spiral-wound modules. A typical TFC membrane has a 0.05-0.2 nm thick active skin layer which is responsible for the separation. The active skin layer sits on top of a polysulfone microporous supporting layer, which is further supported by a polyether non-woven fabric backing layer. The active skin layer of commercial NF/RO membranes typically has a complex structure with a surface roughness of 0.05 to $0.20 \mu \mathrm{m}[27,35]$. The surface roughness of the skin layer can be observed using scanning electron microscopic (SEM), as seen in the image of the ESPA2 RO membrane (Hydranautics) (Figure 9.8) [36], which is used at many water recycling plants. The top dense layer (also called the active skin layer) is responsible for the separation of TrOCs, which selectively pass through the free-volume holes of the membrane (Figure 9.9) [21, 23, 37, 38].

\section{[Figure 9.8]}

[Figure 9.9] 


\subsubsection{Cellulose triacetate}

While a technique for producing a asymmetric cellulose acetate RO membrane was first developed by Loeb and Sourirajan in the 1960s [39], the majority of current membrane manufacturers produce and supply TFC NF/RO membranes. Only a small percent of the RO market uses cellulose triacetate (CTA) RO membranes. Recently, CTA-based RO membranes have re-emerged as they have a significant advantage over TFC RO membranes when treating difficult water with high fouling potential. In fact, CTA membranes can be operated with up to $1 \mathrm{mg} / \mathrm{L}$ chlorine in the feed stream, which can suppress biological growth on the membrane surface. The CTA RO membranes commercially available today are produced as thin hollow fibres ( $<0.2 \mathrm{~mm}$ outer diameter). The water permeability of CTA RO membranes is lower than TFC RO membranes, which requires RO systems using CTA membranes to be operated at a lower permeate flux than systems using TFC membranes. Despite this, systems with CTA RO membranes still have a smaller footprint than systems with TFC RO membranes, because the thin hollow fibres allows a higher membrane packing density in CTA modules [40].

In terms of membrane properties, the free-volume hole radius of CTA RO membranes (0.3 $\mathrm{nm})$ [41] is relatively close to that of typical TFC RO membranes $(0.2-0.29 \mathrm{~nm})$ [25]. Due to the thin structure of hollow fibres $(<0.2 \mathrm{~mm}$ diameter), the measurement of hydrophobicity and zeta potential of these CTA RO membranes is technically very difficult. Similar trends were observed for rejection of neutral TrOCs using typical polyamide and CTA RO membranes [42]. Similar to their polyamide counterparts, the rejection of TrOCs by CTA RO membranes increases with molecular size (e.g. minimum projection area) and hydrophobic interactions can cause deterioration in the rejection of hydrophobic compounds [42]. In contrast, the effect of electrostatic interactions on the rejection of charged TrOCs is less significant for CTA RO membranes compared to their polyamide counterparts. Further membrane characterisation will be useful to precisely describe the solute-membrane interactions.

\subsubsection{Ceramic}

Ceramic NF membranes are a popular choice in water treatment applications where frequent chemical cleaning is required to tackle severe fouling. Commercially available ceramic NF membranes essentially have two layers - a microporous support layer and a thin selective layer. In past decades, relatively loose ceramic NF membranes (MWCO > $400 \mathrm{~g} / \mathrm{mol}$ ) have been used in water treatment applications. Recently, ceramic NF membranes with high 
selectivity (MWCO = $200 \mathrm{~g} / \mathrm{mol}$ ) have emerged. These tight-pore ceramic NF membranes have the potential to reject many TrOCs, because the majority of regulated TrOCs have MWs above $200 \mathrm{~g} / \mathrm{mol}$.

As observed using polymeric NF membranes, the rejection of neutral TrOCs by ceramic NF membranes increases with molecular weight of a compound [17]. However, unlike polymeric NF membranes, the impact of hydrophobic interactions on the rejection of neutral TrOCs by ceramic NF membranes is negligible due to the weak hydrophobicity of ceramic membranes. Furthermore, the rejection of negatively and positively charged compounds by ceramic NF membranes varies significantly as shown in Figure 9.10. The large difference in the observed rejections may be due to the charge concentration polarisation effect (i.e. electrostatic attraction force), which indicates that ceramic membranes have a strong negative charge.

[Figure 9.10]

\subsubsection{Effects of membrane fouling and chemical cleaning}

Membrane fouling is an inherent phenomenon in NF/RO filtration in water recycling applications since municipal and industrial wastewater contains a large amount of foulants including organic and inorganic matter. Typical fouling observed in these applications include organic and colloidal fouling, bio-fouling, and inorganic scales [43]. Due to the deposition of foulants on NF/RO membranes, the alternation of membrane surface properties occurs, resulting in changes in their separation performance. In addition to membrane fouling, membrane surface properties could change with chemical cleaning. Chemical cleaning is periodically performed to remove foulants from the membrane surface and restore its separation performance, while these cleaning agents could chemically change membrane surface properties (e.g. membrane surface charge). Because these membrane surface properties are keys to the rejection of TrOCs, it is important to understand the impact of these factors (i.e. fouling and chemical cleaning) on TrOC rejection for long term system operations.

\subsubsection{Membrane fouling}

While many previous studies examined the effects of membrane fouling on the rejection of TrOCs by NF/RO membranes, the effects reported in literature are generally not consistent. In fact, membrane fouling could both positively and negatively influence TrOC rejection. For example, the rejection of 8 out of 10 TrOCs by an NF membrane (NF-4040, Dow/Filmtec) was reported to increase by up to $20 \%$ with the progress of fouling at a pilot-scale RO 
filtration system [44]. The effects of increased rejections could be due to the formation of organic fouling layer that could increase the negative charge of the membrane surface for negatively charged TrOCs and could increase the adsorption capacity for hydrophobic neutral TrOCs [45]. However, negative or no effect of membrane fouling on TrOC rejection has also been reported for hydrophilic neutral TrOCs $[45,46]$. Hence, the rejection of hydrophilic neutral TrOCs by NF/RO membranes is of significant concern.

Among hydrophilic neutral TrOCs, N-nitrosamines are the most compounds that are often reported to reveal low rejections in water recycling applications. Fujioka et al. [47] evaluated the effects of membrane fouling using tertiary treated wastewater and reported that membrane fouling on three different NF/RO membranes commonly caused an increase in N-nitrosamine rejection (Figure 9.11). The increased rejections were particularly apparent for low molecular weight N-nitrosamines including NDMA. For example, the rejection of NDMA by an RO membrane (ESPA2, Hydranautics/Nitto) increased from 34 to $73 \%$ as fouling progressed (Figure 9.11b). For a high rejection RO membrane (ESPAB, Hydranautics/Nitto), membrane fouling resulted in only a slight increase in NDMA rejection (from 82 to 88\%) (Figure 9.11c). Fujioka et al. [47] suggested that the increased rejections could have been caused by the restriction of compound pathway (e.g. free-volume holes of the active skin layer) with small foulants, improving the size exclusion effect on compound rejection. In fact, a small fraction of low molecular weight organics that could permeate through RO membranes is present in the tertiary effluent [48]. This can also be supported by other experimental results using various model foulants in which the impact of model foulants (i.e. sodium alginate, humic acid, bovine serum albumin, colloidal silica) on N-nitrosamine rejection was minor or negligible [47]. These model foulants are larger in size than the free-volume hole-size of the membrane active skin layer and has a relatively narrow size distribution. As a result, the large model foulants can cause membrane fouling with a cake layer formation only, but it has negligible impact on solute rejection.

\section{[Figure 9.11]}

\subsubsection{Chemical cleaning}

Chemical cleaning on $\mathrm{NF} / \mathrm{RO}$ membranes can cause significant changes in membrane properties including surface charge, hydrophobicity and permeability, resulting in a deterioration in separation performance of the membrane [49]. Chemical cleaning with caustic agents is particularly effective to remove organic fouling from the membrane surface but can 
also alter membrane properties significantly [50-52]. In contrast, the effects of acidic chemical cleaning on membrane properties are less significant [53]. Typical cleaning agents used for chemical cleaning include sodium hydroxide $(\mathrm{NaOH})$, citric acid (CA), hydrochloric acid (HCl), and ethylenediaminetetraacetic acid (EDTA) [54]. In addition, formulated chemical cleaning reagents comprising a variety of chemicals that are typically proprietary information of manufacturers can also be used for chemical cleaning [49]. Caustic chemical cleaning generally causes a decrease in TrOC rejection. In particular, it causes a significant decrease in the rejection of hydrophilic neutral TrOCs (Figure 9.12). Among hydrophilic neutral TrOCs, the impact of chemical cleaning is more apparent for low molecular weight TrOCs, while a negligible impact can be observed for high molecular weight TrOCs [53]. In contrast, the rejection of charged TrOCs is less influenced by chemical cleaning due to the effect of electrostatic repulsion on top of size exclusion mechanism [55].

Simon et al. [55] suggested that the increased rejection of neutral TrOCs by caustic cleaning could be due to the increased pore size of NF membranes by chemical cleaning. In fact, chemical cleaning considerably increased the permeability of NF membranes which is strongly correlated with the pore size of their active skin layer. The same observation (i.e. increased permeability) using caustic cleaning was also observed for polyamide RO membranes [53]. Simon et al. [55] explained this mechanism using a simplified schematic diagram (Figure 9.13). When the membranes are immersed in a high $\mathrm{pH}$ solution (e.g. $\mathrm{pH}>11$ ), the membrane polymer structure is swelled due to the electrostatic repulsion occurring among the deprotonated carboxylic functional groups of the polyamide active skin layer. The swelling effect causes an enlargement of the membrane pore, leading to a significant increase in permeability and a severe deterioration in compound rejection. In contrast, the permeability and rejection capacity of NF membranes at a low $\mathrm{pH}$ (e.g. $\mathrm{pH}<3$ ) remains almost unchanged from a neutral $\mathrm{pH}$ (e.g. $\mathrm{pH}$ 7), because the polyamide membranes have an isoelectric point at approximately $\mathrm{pH} 3$ and their weakly or not charged carboxylic functional groups do not enlarge the pores of the active skin layer. Interestingly, the changes in pore structure caused by a high $\mathrm{pH}$ solution can be reversible as reported by Simon et al. [55]. For example, the decreased TrOC rejections caused by caustic cleaning were fully recovered by applying acidic cleaning for 4 hours [55]. The same observations using polyamide RO membranes have also been reported in literature [53]. These results suggest that a sequence of caustic followed by acidic cleaning can restore the separation capability of NF/RO membranes.

[Figure 9.12] 


\section{[Figure 9.13]}

\subsection{Other membrane processes}

\subsubsection{Forward osmosis}

FO is an osmotically driven process. Similar to RO, FO uses a semi-permeable membrane to effect separation of water from dissolved solutes. The driving force for this separation is an osmotic pressure gradient created by a draw solution of higher concentration (compared to that of the feed solution) that induces the flow of water through the membrane into the draw solution, thus effectively separating the feed water from its solutes. FO has been extensively investigated in recent years for water and wastewater treatment. When a draw solution (such as seawater) is freely and readily available FO can be a standalone process. However, in most cases, FO is used as an advanced pre-treatment for downstream processes such as RO and thermal distillation.

To date, more than a dozen studies have been conducted to investigate the rejection of emerging trace organic contaminants by FO [56]. Overall, the rejection mechanisms are similar to that by NF/RO membranes. In other words, the rejections of emerging trace organic contaminants are governed mostly by size exclusion (or steric interaction) and electrostatic interaction. Affinity of specific organic molecule toward FO membrane (e.g., through hydrophobic interaction) may also influence the rejection, particularly when the solute is comparable or smaller to the pore size of the FO membrane.

Alturki et al., [57] studied the rejection of a large range of trace organic contaminants by a cellulose triacetate (CTA) membrane from HTI Inc. Their results demonstrate that the rejection of neutral trace organic contaminants increase as the compound molecular weight increases (Figure 9.14). FO membranes are asymmetric, they can be deployed in either the FO mode (i.e., the membrane active layer is in contact with the feed solution) or the pressure retarded osmosis (PRO) mode (i.e., the membrane active layer is in contact with the draw solution). Data reported by Alturki et al., [57] showed that the PRO mode can produce a higher water flux but lead to a notably lower TrOC rejection compared to the FO mode (Figure 9.14). It was also shown that the rejection of charged TrOCs is higher than their neutral counterpart with a similar molecular weight (Figure 9.14). These findings are supported by Coday et al., [56] who corroborated TrOC rejection data from 14 recent FO studies (Figure 9.15). 


\section{[Figure 9.14]}

\section{[Figure 9.15]}

Coday et al., [56] reported that membrane fouling can considerably alter TrOC rejection by FO. The exact reasons for these variations in TrOC rejection when the membrane is fouled remain unclear. However, similar to the NF/RO process, cake-enhanced concentration polarisation, addition filtration layer, and the disruption of affinity interaction between TrOC and the membrane polymeric surface can be the possible mechanisms.

Unlike NF/RO, solute transport in FO is bi-directional and could result in an interesting phenomenon known as 'retarded forward diffusion' (Figure 9.16). Retarded forward diffusion is a phenomenon first demonstrated by Xie et al., [58] who have conducted the most thorough investigations of the impact of draw solute diffusion on TrOC rejection. By examining several different draw solutes (i.e. $\mathrm{NaCl}, \mathrm{MgSO}_{4}$, glucose, and urea), Xie et al., [58] demonstrated that the forward diffusion of TrOCs could be hindered by the reverse diffusion of solutes from the draw solution to the feed. As a result, TrOC rejection can be enhanced by a high reverse salt flux.

\section{[Figure 9.16]}

\subsubsection{Membrane distillation}

Membrane distillation (MD) is a low temperature distillation process that involves the transport of water in the vapour phase from a feed solution through a microporous and hydrophobic membrane to the distillate (product) side. The feed solution is maintained at a high temperature to create a vapour pressure difference between the feed and distillate. In MD, liquid water cannot be transported through the membrane but water vapour (gas phase) can freely move through the membrane dry micro-porous pores from the feed to the distillate. To prevent the penetration of liquid water to the pores, the membrane material must be hydrophobic (i.e., contact angle of more than $90^{\circ}$ ). Because mass transfer can occur only in the gas phase, MD can offer complete rejection of all non-volatile solutes such as inorganic salts and pathogenic agents. To date, much of the effort in MD research has focused on desalination applications. However, when waste heat or solar thermal is readily available, MD can potentially be used for the production of high quality distillate for water recycling applications [59]. 
Despite the growing interest in using MD for treatment of a range of wastewaters, there is still a lack of understanding of the removal of TrOCs by MD. Only a few studies have been conducted to elucidate the rejection of specific organic compounds by MD. Moreover, most of these are concerned with industrial chemicals such as benzene [60] and trichloroethylene [61] at an elevated feed concentration. Two recent studies by Wijekoon et al., [62, 63] are the only exception.

Wijekoon et al., [62] reported the first comprehensive investigation of TrOC removal by MD involving 29 compounds that occur ubiquitously in municipal wastewater. They demonstrated that the removal and fate and transport of TrOC during MD are governed by their volatility and, to a lesser extent, hydrophobicity (Figure 9.17). The Henry's law constant $(\mathrm{H})$ or $\mathrm{pK}_{\mathrm{H}}$ (which is defined as $\mathrm{pK}_{\mathrm{H}}=-\mathrm{Log}_{10} \mathrm{H}$ ) can be used to assess the volatility of TrOCs. Physical parameters (i.e., vapour pressure, molecular weight (MW), and water solubility) of all TrOCs are readily available and can be used to calculate the Henry's law constant as: $\mathrm{H}$ (atm. $\mathrm{m}^{3} / \mathrm{mol}$ ) $=$ Vapour pressure $\times \mathrm{MW} /$ water solubility. Wijekoon et al., [62] showed that all TrOCs with $\mathrm{pK}_{\mathrm{H}}>9$ (which can be classified as non-volatile) were well removed by MD. Among the 29 TrOCs investigated in this study, three compounds (i.e. 4-tert-octylphenol, 4-tert-butylphenol and benzophenone) possess moderate volatility $\left(\mathrm{pK}_{\mathrm{H}}<9\right)$ and therefore had the lowest rejection efficiencies of 54, 73 and 66\%, respectively (Figure 9.17).

\section{[Figure 9.17]}

Wijekoon et al., [62] also hypothesized that the rejection of TrOCs with $\mathrm{pK}_{\mathrm{H}}<9$ is governed by the interplay between their hydrophobicity and volatility. Hydrophilic TrOCs having negligible volatility were concentrated in the feed, while hydrophobic compounds with moderate volatility were substantially lost due to evaporation or adsorption. When MD treatment was integrated with a thermophilic membrane bioreactor (MBR), near complete removal (> 95\%) of all 29 TrOCs investigated in this study was achieved despite their diverse physicochemical properties (i.e. hydrophobicity, persistency and volatility). The results suggest that MD could be a promising post-treatment to be used in conjunction with thermophilic MBR for TrOC removal.

In a subsequent investigation, Wijekoon and co-workers [63] demonstrated that MD can complement thermophilic biological treatment to enhance the removal of TrOCs. All TrOCs investigated in their study were highly removed (> 95\%) by an integrated MD - thermophilic bioreactor system. They [63] also noted a major challenge to overcome the build-up of 
salinity in the bioreactor due to the high salt rejection of the MD process, which may gradually compromise biological treatment.

\subsubsection{Membrane electrodialysis}

Membrane electrodialysis (ED) is another desalting process that has also been investigated for the removal of TrOCs. In ED, cations and anions are transported through ion exchange membranes away from the feed under the influence of an applied electric potential difference (Figure 9.18) [64]. Cations moves through the cation-exchange membrane toward the cathode while anions moves through the anion-exchange toward the anode. ED can be advantageous over many other desalting processes when the quantity of salt ions in the feed stream is small and they are highly mobile. The mobility of ionisable TrOCs are significantly lower than that of inorganic salts, thus, a primary interest in the removal of TrOC by ED is in the desalting of RO brine from water recycling applications.

\section{[Figure 9.18]}

In general, the removal of TrOCs by ED appears to be lower compared to all other membrane processes discussed in this chapter. Banasiak and Schafer [65] showed that neutral and hydrophobic TrOCs such as steroid hormones can adsorb significantly to the ion exchange membrane. This adsorption results in a temporarily high removal but only during the initial stage. A similar finding was reported by Vanoppen et al., [66] who studied the transport of 15 TrOCs during ED. As expected, Vanoppen et al., also showed that the transport (i.e. removal) of charged TrOCs was significantly higher than neutral TrOCs which was driven mostly by diffusion. In addition, they reported a competition for ED transportation between charged TrOCs and $\mathrm{NaCl}$ (which was used as a model inorganic salt). The transport of charged TrOCs decreased significantly in the presence of $\mathrm{NaCl}$.

\section{Conclusion}

This chapter described in details the separation of trace organic contaminants (TrOCs) by nanofiltration (NF) and reverse osmosis (RO) membranes. Recent advance in positron annihilation life-time spectroscopy (PALS) has allowed for the characterisation of the free hole volume radii of the NF/RO membrane active layer. TrOC rejection by NF/RO membranes are governed by size exclusion, electrostatic interaction, and hydrophobic interaction. Among these three mechanisms, size exclusion appears to the dominating one. Indeed, electrostatic and hydrophobic interactions are only relevant when the molecular 
dimension of TrOCs are comparable to that of the membrane free hole volume radius. Although the rejections of TrOCs by NF/RO membranes of different materials (e.g. polyamide, cellulose triacetate, and ceramic) are broadly similar, there are some interesting variations. For examples, the effects of electrostatic interactions on the rejection of charged TrOCs is less significant for CTA RO membranes compared to their polyamide counterparts. In addition, the rejections of positively charged TrOCs by ceramic membranes were considerably lower than those of negatively charged compounds. Such variation between positively and negatively charged TrOCs was not observed for polyamide NF/RO membranes. It is noteworthy that membrane fouling and chemical cleaning could exert markedly influence on the rejection of TrOCs by NF/RO membranes.

The removal of TrOCs by several other membrane processes including forward osmosis (FO), membrane distillation (RO), and membrane electrodialysis (ED) was also briefly reviewed. The separation of TrOCs by FO is similar to that by NF/RO. TrOC rejection by MD depends mostly on their volatility. In addition, hydrophobic interaction may also play a role in governing the rejection of TrOCs by MD. ED can only be used for removed charged TrOCs. In general, the removal efficiency by ED is low and can be negatively influenced by the presence of inorganic salts in the feed solution.

\section{References}

[1] Y. Luo, W. Guo, H.H. Ngo, L.D. Nghiem, F.I. Hai, J. Zhang, S. Liang, X.C. Wang, A review on the occurrence of micropollutants in the aquatic environment and their fate and removal during wastewater treatment, Science of the Total Environment, 473-474 (2014) 619-641.

[2] M. Farré, L. Kantiani, M. Petrovic, S. Pérez, D. Barceló, Achievements and future trends in the analysis of emerging organic contaminants in environmental samples by mass spectrometry and bioanalytical techniques, Journal of Chromatography A, 1259 (2012) 86-99.

[3] T. Fujioka, S.J. Khan, Y. Poussade, J.E. Drewes, L.D. Nghiem, N-nitrosamine removal by reverse osmosis for indirect potable water reuse - A critical review based on observations from laboratory-, pilot- and full-scale studies, Separation and Purification Technology, 98 (2012) 503-515.

[4] NHMRC, NRMMC, Australian drinking water guidelines paper 6 national water quality management strategy, National Healthand Medical Research Council, National Resource Management Ministerial Council, Commonwealth of Australia, Canberra, 2011.

[5] NRMMC, EPHC, AHMC, Australian guidelines for water recycling: Managing health and environmental risks (Phase 2): Augmentation of drinking water supplies, Environment Protection and Heritage Council, National Health and Medical Research Council, Natural Resource Management Ministerial Council, Canberra, 2008. 
[6] IARC, IARC monographs on the evaluation of carcinogenic risks to humans: Overall evaluations of carcinogenicity: An updating of IARC monographs volumes 1 - 42: Supplement 7, International agency for research on cancer, (1987).

[7] CDPH, NDMA and other Nitrosamines - Drinking water issues (http://www.cdph.ca.gov/certlic/drinkingwater/Pages/NDMA.aspx), $\quad$ California Department of Public Health 2011.

[8] Ontario MOE, Technical support document for Ontario drinking water standards, objectives and guidelines, Ontario Ministry of the Environment, Ontario, 2003.

[9] WHO, Guidelines for drinking-water quality 4th edition - N-Nitrosodimethylamine (NDMA), in, World Health Organization, Geneva, 2011.

[10] F. Beyer, B.M. Rietman, A. Zwijnenburg, P. van den Brink, J.S. Vrouwenvelder, M. Jarzembowska, J. Laurinonyte, A.J.M. Stams, C.M. Plugge, Long-term performance and fouling analysis of full-scale direct nanofiltration (NF) installations treating anoxic groundwater, Journal of Membrane Science, 468 (2014) 339-348.

[11] C. Ventresque, V. Gisclon, G. Bablon, G. Chagneau, Outstanding feat of modern technology: the Mery-sur-Oise nanofiltration treatment plant (340,000 m3/d), Desalination, 131 (2000) 1-16.

[12] C. Bellona, J.E. Drewes, P. Xu, G. Amy, Factors affecting the rejection of organic solutes during NF/RO treatment - A literature review, Water Res., 38 (2004) 27952809.

[13] B. Van der Bruggen, C. Vandecasteele, Modelling of the retention of uncharged molecules with nanofiltration, Water Res., 36 (2002) 1360-1368.

[14] B. Van der Bruggen, J. Schaep, D. Wilms, C. Vandecasteele, Influence of molecular size, polarity and charge on the retention of organic molecules by nanofiltration, J. Membr. Sci., 156 (1999) 29-41.

[15] Y. Kiso, T. Kitao, K. Jinno, M. Miyagi, The effects of molecular width on permeation of organic solute through cellulose acetate reverse osmosis membranes, J. Membr. Sci., 74 (1992) 95-103.

[16] Y. Kiso, K. Muroshige, T. Oguchi, M. Hirose, T. Ohara, T. Shintani, Pore radius estimation based on organic solute molecular shape and effects of pressure on pore radius for a reverse osmosis membrane, J. Membr. Sci., 369 (2011) 290-298.

[17] T. Fujioka, S.J. Khan, J.A. McDonald, L.D. Nghiem, Nanofiltration of trace organic chemicals: A comparison between ceramic and polymeric membranes, Sep. Purif. Technol., 136 (2014) 258-264.

[18] K.O. Agenson, J.-I. Oh, T. Urase, Retention of a wide variety of organic pollutants by different nanofiltration/reverse osmosis membranes: controlling parameters of process, J. Membr. Sci., 225 (2003) 91-103.

[19] B. Van der Bruggen, J. Schaep, W. Maes, D. Wilms, C. Vandecasteele, Nanofiltration as a treatment method for the removal of pesticides from ground waters, Desalination, 117 (1998) 139-147.

[20] R. Suzuki, Y. Kobayashi, T. Mikado, H. Ohgaki, M. Chiwaki, T. Yamazaki, T. Tomimasu, Slow positron pulsing system for variable energy positron lifetime spectroscopy, Jpn. J. Appl. Phys., 30 (1991) 532-534.

[21] Y.C. Jean, J.D. Van Horn, W.-S. Hung, K.-R. Lee, Perspective of Positron Annihilation Spectroscopy in Polymers, Macromolecules, 46 (2013) 7133-7145.

[22] Y.C. Jean, W.-S. Hung, C.-H. Lo, H. Chen, G. Liu, L. Chakka, M.-L. Cheng, D. Nanda, K.-L. Tung, S.-H. Huang, K.-R. Lee, J.-Y. Lai, Y.-M. Sun, C.-C. Hu, C.-C. Yu, Applications of positron annihilation spectroscopy to polymeric membranes, Desalination, 234 (2008) 89-98. 
[23] S.H. Kim, S.-Y. Kwak, T. Suzuki, Positron Annihilation Spectroscopic Evidence to Demonstrate the Flux-Enhancement Mechanism in Morphology-Controlled ThinFilm-Composite (TFC) Membrane, Environ. Sci. Technol., 39 (2005) 1764-1770.

[24] Z. Chen, K. Ito, H. Yanagishita, N. Oshima, R. Suzuki, Y. Kobayashi, Correlation study between free-volume holes and molecular separations of composite membranes for reverse osmosis processes by means of variable-energy positron annihilation techniques, J. Phys. Chem. C, 115 (2011) 18055-18060.

[25] T. Fujioka, N. Oshima, R. Suzuki, W.E. Price, L.D. Nghiem, Probing the internal structure of reverse osmosis membranes by positron annihilation lifetime spectroscopy: Gaining more insight into the transport of water and small solutes, Journal of Membrane Science, (Accepted on 7th February 2015).

[26] M. Henmi, Y. Fusaoka, H. Tomioka, M. Kurihara, High performance RO membranes for desalination and wastewater reclamation and their operation results, Water Sci. Technol., 62 (2010) 2134-2140.

[27] C.Y. Tang, Y.-N. Kwon, J.O. Leckie, Effect of membrane chemistry and coating layer on physiochemical properties of thin film composite polyamide RO and NF membranes: II. Membrane physiochemical properties and their dependence on polyamide and coating layers, Desalination, 242 (2009) 168-182.

[28] C. Bartels, M. Wilf, W. Casey, J. Campbell, New generation of low fouling nanofiltration membranes, Desalination, 221 (2008) 158-167.

[29] T. Fujioka, S.J. Khan, J.A. McDonald, L.D. Nghiem, Validating the rejection of trace organic chemicals of significant health concern by reverse osmosis membranes using a pilot-scale system, Desalination, 358 (2015) 18-26.

[30] A.R.D. Verliefde, E.R. Cornelissen, S.G.J. Heijman, J.Q.J.C. Verberk, G.L. Amy, B. Van der Bruggen, J.C. van Dijk, The role of electrostatic interactions on the rejection of organic solutes in aqueous solutions with nanofiltration, J. Membr. Sci., 322 (2008) 52-66.

[31] B. Van der Bruggen, A. Verliefde, L. Braeken, E.R. Cornelissen, K. Moons, J.Q.J.C. Verberk, H.J.C. van Dijk, G. Amy, Assessment of a semi-quantitative method for estimation of the rejection of organic compounds in aqueous solution in nanofiltration, Journal of Chemical Technology and Biotechnology, 81 (2006) 1166-1176.

[32] K. Kimura, G. Amy, J.E. Drewes, T. Heberer, T.-U. Kim, Y. Watanabe, Rejection of organic micropollutants (disinfection by-products, endocrine disrupting compounds, and pharmaceutically active compounds) by NF/RO membranes, J. Membr. Sci., 227 (2003) 113-121.

[33] J.E. Cadotte, L.T. Rozelle, In-situ formed condensation polymers for reverse osmosis membranes, OSW PB-Report, No 927.

[34] R.E. Larson, J.E. Cadotte, R.J. Petersen, The FT-30 seawater reverse osmosis membrane--element test results, Desalination, 38 (1981) 473-483.

[35] B. Mi, O. Coronell, B.J. Mariñas, F. Watanabe, D.G. Cahill, I. Petrov, Physicochemical characterization of NF/RO membrane active layers by Rutherford backscattering spectrometry, J. Membr. Sci., 282 (2006) 71-81.

[36] H. Yan, X. Miao, J. Xu, G. Pan, Y. Zhang, Y. Shi, M. Guo, Y. Liu, The porous structure of the fully-aromatic polyamide film in reverse osmosis membranes, $\mathrm{J}$. Membr. Sci., 475 (2015) 504-510.

[37] J. Wang, D.S. Dlamini, A.K. Mishra, M.T.M. Pendergast, M.C.Y. Wong, B.B. Mamba, V. Freger, A.R.D. Verliefde, E.M.V. Hoek, A critical review of transport through osmotic membranes, J. Membr. Sci., 454 (2014) 516-537. 
[38] A. Shimazu, K. Ikeda, T. Miyazaki, Y. Ito, Application of positron annihilation technique to reverse osmosis membrane materials, Radiation Physics and Chemistry, 58 (2000) 555-561.

[39] S. Loeb, S. Sourirajan, Sea Water Demineralization by Means of an Osmotic Membrane, in: Saline Water Conversion II, American Chemical Society, 1963, pp. 117-132.

[40] A. Kumano, M. Sekino, Y. Matsui, N. Fujiwara, H. Matsuyama, Study of mass transfer characteristics for a hollow fiber reverse osmosis module, J. Membr. Sci., 324 (2008) 136-141.

[41] H. Hagihara, K. Ito, N. Oshima, A. Yabuuchi, H. Suda, H. Yanagishita, Depth profiling of the free-volume holes in cellulose triacetate hollow-fiber membranes for reverse osmosis by means of variable-energy positron annihilation lifetime spectroscopy, Desalination, 344 (2014) 86-89.

[42] T. Fujioka, S.J. Khan, J.A. McDonald, L.D. Nghiem, Rejection of trace organic chemicals by a hollow fibre cellulose triacetate reverse osmosis membrane, Desalination, In Press, Corrected Proof (2015).

[43] P. Xu, C. Bellona, J.E. Drewes, Fouling of nanofiltration and reverse osmosis membranes during municipal wastewater reclamation: Membrane autopsy results from pilot-scale investigations, J. Membr. Sci., 353 (2010) 111-121.

[44] C. Bellona, J.E. Drewes, Viability of a low-pressure nanofilter in treating recycled water for water reuse applications: A pilot-scale study, Water Res., 41 (2007) 39483958.

[45] P. Xu, J.E. Drewes, T.-U. Kim, C. Bellona, G. Amy, Effect of membrane fouling on transport of organic contaminants in NF/RO membrane applications, J. Membr. Sci., 279 (2006) 165-175.

[46] H.Y. Ng, M. Elimelech, Influence of colloidal fouling on rejection of trace organic contaminants by reverse osmosis, J. Membr. Sci., 244 (2004) 215-226.

[47] T. Fujioka, S.J. Khan, J.A. McDonald, R.K. Henderson, Y. Poussade, J.E. Drewes, L.D. Nghiem, Effects of membrane fouling on N-nitrosamine rejection by nanofiltration and reverse osmosis membranes, J. Membr. Sci., 427 (2013) 311-319.

[48] T. Fujioka, N. Oshima, R. Suzuki, M. Higgins, W.E. Price, R.K. Henderson, L.D. Nghiem, Effect of heat treatment on fouling resistance and the rejection of small and neutral solutes by reverse osmosis membranes, Water Science \& Technology: Water Supply, Article in Press (Accepted on 10th December 2014).

[49] A. Simon, W.E. Price, L.D. Nghiem, Influence of formulated chemical cleaning reagents on the surface properties and separation efficiency of nanofiltration membranes, J. Membr. Sci., 432 (2013) 73-82.

[50] R. Liikanen, J. Yli-Kuivila, R. Laukkanen, Efficiency of various chemical cleanings for nanofiltration membrane fouled by conventionally-treated surface water, J. Membr. Sci., 195 (2002) 265-276.

[51] S.S. Madaeni, Y. Mansourpanah, Chemical cleaning of reverse osmosis membranes fouled by whey, Desalination, 161 (2004) 13-24.

[52] A. Simon, W.E. Price, L.D. Nghiem, Effects of chemical cleaning on the nanofiltration of pharmaceutically active compounds (PhACs), Sep. Purif. Technol., 88 (2012) 208215.

[53] T. Fujioka, S.J. Khan, J.A. McDonald, A. Roux, Y. Poussade, J.E. Drewes, L.D. Nghiem, N-nitrosamine rejection by reverse osmosis: Effects of membrane exposure to chemical cleaning reagents, Desalination, 343 (2014) 60-66. 
[54] Q. Li, M. Elimelech, Organic fouling and chemical cleaning of nanofiltration membranes: measurements and mechanisms, Environ. Sci. Technol., 38 (2004) 46834693.

[55] A. Simon, J.A. McDonald, S.J. Khan, W.E. Price, L.D. Nghiem, Effects of caustic cleaning on pore size of nanofiltration membranes and their rejection of trace organic chemicals, J. Membr. Sci., 447 (2013) 153-162.

[56] B.D. Coday, B.G.M. Yaffe, P. Xu, T.Y. Cath, Rejection of trace organic compounds by forward osmosis membranes: A literature review, Environmental Science and Technology, 48 (2014) 3612-3624.

[57] A.A. Alturki, J.A. McDonald, S.J. Khan, W.E. Price, L.D. Nghiem, M. Elimelech, Removal of trace organic contaminants by the forward osmosis process, Separation and Purification Technology, 103 (2013) 258-266.

[58] M. Xie, L.D. Nghiem, W.E. Price, M. Elimelech, Comparison of the removal of hydrophobic trace organic contaminants by forward osmosis and reverse osmosis, Water Research, 46 (2012) 2683-2692.

[59] R.G. Raluy, R. Schwantes, V.J. Subiela, B. Peñate, G. Melián, J.R. Betancort, Operational experience of a solar membrane distillation demonstration plant in Pozo Izquierdo-Gran Canaria Island (Spain), Desalination, 290 (2012) 1-13.

[60] F.A. Banat, J. Simandl, Removal of benzene traces from contaminated water by vacuum membrane distillation, Chemical Engineering Science, 51 (1996) 1257-1265.

[61] S. Duan, A. Ito, A. Ohkawa, Removal of trichloroethylene from water by aeration, pervaporation and membrane distillation, Journal of Chemical Engineering of Japan, 34 (2001) 1069-1073.

[62] K.C. Wijekoon, F.I. Hai, J. Kang, W.E. Price, T.Y. Cath, L.D. Nghiem, Rejection and fate of trace organic compounds (TrOCs) during membrane distillation, Journal of Membrane Science, 453 (2014) 636-642.

[63] K.C. Wijekoon, F.I. Hai, J. Kang, W.E. Price, W. Guo, H.H. Ngo, T.Y. Cath, L.D. Nghiem, A novel membrane distillation-thermophilic bioreactor system: Biological stability and trace organic compound removal, Bioresource Technology, 159 (2014) 334-341.

[64] S.E. Kentish, E. Kloester, G.W. Stevens, C.A. Scholes, L.F. Dumée, Electrodialysis in aqueous-organic mixtures, Separation and Purification Reviews, 44 (2015) 269-282.

[65] L.J. Banasiak, A.I. Schäfer, Sorption of steroidal hormones by electrodialysis membranes, Journal of Membrane Science, 365 (2010) 198-205.

[66] M. Vanoppen, A.F.A.M. Bakelants, D. Gaublomme, K.V.K.M. Schoutteten, J. Van Den Bussche, L. Vanhaecke, A.R.D. Verliefde, Properties governing the transport of trace organic contaminants through ion-exchange membranes, Environmental Science and Technology, 49 (2015) 489-497. 
Table 9.1: Risk level and guideline level of N-nitrosamines.

\begin{tabular}{lcccccc}
\hline Compound & $\begin{array}{c}\text { IARC } \\
\text { classifica } \\
\text { tion }^{\text {a }}\end{array}$ & $\begin{array}{c}\text { CDPH } \\
\text { notification } \\
\text { level } \\
{[\mathrm{ng} / \mathrm{L}]}\end{array}$ & $\begin{array}{c}\text { Ontario MOE } \\
\text { an interim } \\
\text { action level } \\
{[\mathrm{ng} / \mathrm{L}]}\end{array}$ & $\begin{array}{c}\text { WHO } \\
\text { guideline } \\
\text { value } \\
{[\mathrm{ng} / \mathrm{L}]}\end{array}$ & $\begin{array}{c}\text { ADWG } \\
\text { guideline } \\
\text { value } \\
{[\mathrm{ng} / \mathrm{L}]}\end{array}$ & $\begin{array}{c}\text { AGWR } \\
\text { guideline } \\
\text { value } \\
{[\mathrm{ng} / \mathrm{L}]}\end{array}$ \\
\hline NDMA & 2A & 10 & 9 & 100 & 100 & 10 \\
NDEA & 2A & 10 & - & - & - & 10 \\
NMOR & 2B & - & - & - & - & 1 \\
\hline Reference & {$[6]$} & {$[7]$} & {$[8]$} & {$[9]$} & {$[4]$} & {$[5]$} \\
\hline
\end{tabular}

${ }^{\mathrm{a}}$ 2A: probable human carcinogen; 2B: possibly human carcinogen.

NDEA: n-Nitrosodiethylamine; NMOR: n-Nitrosomorpholine; IARC: International Agency for Research on Cancer; CDPH: California Department of Public Health; Ontario MOE: Ontario Ministry of the Environment; WHO: World Health Organisation; ADWG: Australian Drinking Water Guidelines; AGWR: Australian Guidelines for Water Recycling. 
Table 9.2: Examples of full scale NF/RO plants for either drinking water production or water recycling.

\begin{tabular}{|c|c|c|c|c|}
\hline Plant & $\begin{array}{l}\text { Capacity } \\
\left(\mathrm{m}^{3} / \mathrm{d}\right)\end{array}$ & Membrane & Application & Reference \\
\hline $\begin{array}{l}\text { Diepenveen, The } \\
\text { Netherlands }\end{array}$ & 4,600 & TS82 NF & Drinking water & [10] \\
\hline $\begin{array}{l}\text { Mery-sur-Oise, Paris, } \\
\text { France }\end{array}$ & 340,000 & NF-200 & Drinking water & [11] \\
\hline $\begin{array}{l}\text { West Basin, California, } \\
\text { USA }\end{array}$ & 75,700 & TFC-HR & Water recycling & [3] \\
\hline $\begin{array}{l}\text { Bundamba, Queensland, } \\
\text { Australia }\end{array}$ & 66,000 & TFC-HR & Water recycling & [3] \\
\hline
\end{tabular}


Table 9.3: Zeta potential of fully aromatic polyamide commercial NF/RO membranes [27].

\begin{tabular}{lll}
\hline Membrane & & $\begin{array}{l}\text { Zeta potential } \\
\text { at pH 9 [mV] }\end{array}$ \\
\hline Uncoated & SWC4 & -20.9 \\
& XLE & -27.8 \\
& LE & -26.1 \\
& ESPA3 & -24.8 \\
& NE90 & -21.0 \\
& NF90 & -37.0 \\
\hline Coated & SW30HR & -1.7 \\
& LFC1 & -13.2 \\
& LFC3 & -6.5 \\
& BW30 & -10.1 \\
\hline
\end{tabular}




\section{List of Figures}

Figure 9.1: Major pathways for emerging contaminants to enter the environment.

Figure 9.2: Schematic figure of the minimum projection area of a molecule. Molecular width $(\mathrm{MWd})$ is defined as a half of the square root of the minimum projection area. $\mathrm{MWd}=$ $0.5(S)^{0.5}, S=[(\mathrm{B} 1+\mathrm{B} 4) \times(\mathrm{B} 2+\mathrm{B} 3)]$ (Reproduced with permission from Ref. [16]. Copyright 2011 Elsevier Science).

Figure 9.3: Rejection of neutral TrOCs by NF90 membrane as a function of (a) molecular weight and (b) minimum projection area $(20 \mathrm{mM} \mathrm{NaCl}, 1 \mathrm{mM} \mathrm{NaHCO}, 1 \mathrm{mM} \mathrm{CaCl}$, permeate flux $20 \mathrm{~L} / \mathrm{m}^{2} \mathrm{~h}$, feed $\mathrm{pH} 8.0 \pm 0.1$, feed temperature $20.0 \pm 0.1^{\circ} \mathrm{C}$ ) (Reproduced with permission from Ref. [17]. Copyright 2014 Elsevier Science).

Figure 9.4: Speciation of ibuprofen $(\mathrm{pKa}=4.9)$ and amitriptyline $(\mathrm{pKb}=9.8)$ as a function of $\mathrm{pH}$. At a solution $\mathrm{pH}$ of 8 , ibuprofen and amitriptyline exist as negatively and positively charged species respectively.

Figure 9.5: Zeta potential of the virgin ESPA2 membrane as a function of $\mathrm{pH}$ at $30{ }^{\circ} \mathrm{C}(1 \mathrm{mM}$ $\mathrm{KCl}$ solution, values reported as average and range of duplicate results).

Figure 9.6: The rejection of neutral \& charged TrOCs by the NF270 membrane as a function of minimum projection area (20 mM NaCl, $1 \mathrm{mM} \mathrm{NaHCO}_{3}, 1 \mathrm{mM} \mathrm{CaCl}_{2}$, permeate flux 20 $\mathrm{L} / \mathrm{m}^{2} \mathrm{~h}$, feed $\mathrm{pH} 8.0 \pm 0.1$, feed temperature $20.0 \pm 0.1^{\circ} \mathrm{C}$ ) (Reproduced with permission from Ref. [17]. Copyright 2014 Elsevier Science).

Figure 9.7: Change in 2-naphthol concentration during filtration test using ESNA membrane (Reproduced with permission from Ref. [32]. Copyright 2003 Elsevier Science).

Figure 9.8: Scanning electron microscopy cross-section image of ESPA2 membrane showing (a) the position of a dense layer with an average thickness of $20 \mathrm{~nm}$ (cutting lines) and passages for filtrate flow under pressure (dotted lines) and (b) fractured ridge structure with a cavity on the root (Reproduced with permission from Ref. [36]. Copyright 2014 Elsevier Science).

Figure 9.9: Schematic molecular structure of cross-linked polyamide chains in a typical TFC RO membrane [38].

Figure 9.10: Rejection of charged TrOCs by a (a) ceramic membrane and (b) NF90 membrane as a function of minimum projection area (Reproduced with permission from Ref. [17]. Copyright 2014 Elsevier Science).

Figure 9.11: Effects of membrane fouling using tertiary effluent on the rejection of $\mathrm{N}$ nitrosamines by ESPA2 membrane (permeate flux $20 \mathrm{~L} / \mathrm{m}^{2} \mathrm{~h}$, cross flow velocity $40.2 \mathrm{~cm} / \mathrm{s}$, feed temperature $20.0 \pm 0.1^{\circ} \mathrm{C}$ ). (Reproduced with permission from Ref. [47]. Copyright 2012 Elsevier Science). 
Figure 9.12: Rejection of neutral hydrophilic TrOC ( $\log D<3)$ after 24 h of filtration as a function of the compounds equivalent width by the virgin and chemically cleaned (a) NF270 and (b) NF90 membrane. (Reproduced with permission from Ref. [55]. Copyright 2013 Elsevier Science).

Figure 9.13: Schematic drawing of a membrane top layer as a function of the membrane charge (i.e., background $\mathrm{pH}$ ). (a) Shrinkage of the membrane matrix due to acidic cleaning rendering the membrane neutral, (b) Membrane matrix under a normal $\mathrm{pH}$ condition, (c) Swelling of the membrane matrix due to caustic cleaning and (d) Swollen membrane matrix subsequently after caustic cleaning in a normal $\mathrm{pH}$ environment. (Reproduced with permission from Ref. [49]. Copyright 2012 Elsevier Science).

Figure 9.14: The rejection of neutral TrOCs by the HTI membrane as a function of molecular weight in (a) PRO and (b) FO modes. (Reproduced with permission from Ref. [57]. Copyright 2013 Elsevier Science).

Figure 9.15: Average rejection of TrOCs by virgin and fouled FO CTA membranes tested at the bench scale. Only those results from experiments that used $\mathrm{NaCl}$ or seawater draw solution are shown. TrOCs are grouped on the basis of their physiochemical composition near neutral $\mathrm{pH}$ and are ordered by increasing molecular weight (MW, no. of studies). Error bars represent the standard deviation between multiple sample results for individual studies and between sample results reported by multiple studies. (Reproduced with permission from Ref. [56]. Copyright 2014 ACS).

Figure 9.16: Schematic diagram representing the retarded forward diffusion of feed solutes in the FO process by the reverse draw solutes. (Reproduced with permission from Ref. [58]. Copyright 2012 Elsevier Science).

Figure 9.17: Rejection of the 29 TrOCs by DCMD and their $\log D$ and $\mathrm{pK}_{\mathrm{H}}$ values. $\log D$ and $\mathrm{pK}_{\mathrm{H}}$ illustrate the values at the $\mathrm{pH}$ 9. Error bars represent the standard deviation from four replicate measurements. Synthetic solution containing approximately $5 \mu \mathrm{g} / \mathrm{L}$ of each TrOC in Milli-Q water was used as the feed. The MD was carried out at the feed and distillate temperatures of 40 and $20^{\circ} \mathrm{C}$, respectively. The feed and distillate circulation flow rate was 2 $\mathrm{L} / \mathrm{min}$ (corresponding to $11.7 \mathrm{~cm} / \mathrm{s}$ ). (Reproduced with permission from Ref. [62]. Copyright 2013 Elsevier Science).

Figure 9.18: Schematic diagram of an electrodialysis stack operating on a solution of sodium chloride. $\mathrm{A}=$ Anion exchange membrane, $\mathrm{C}=$ Cation Exchange membrane. (Reproduced with permission from Ref. [64]. Copyright 2013 Elsevier Science). 


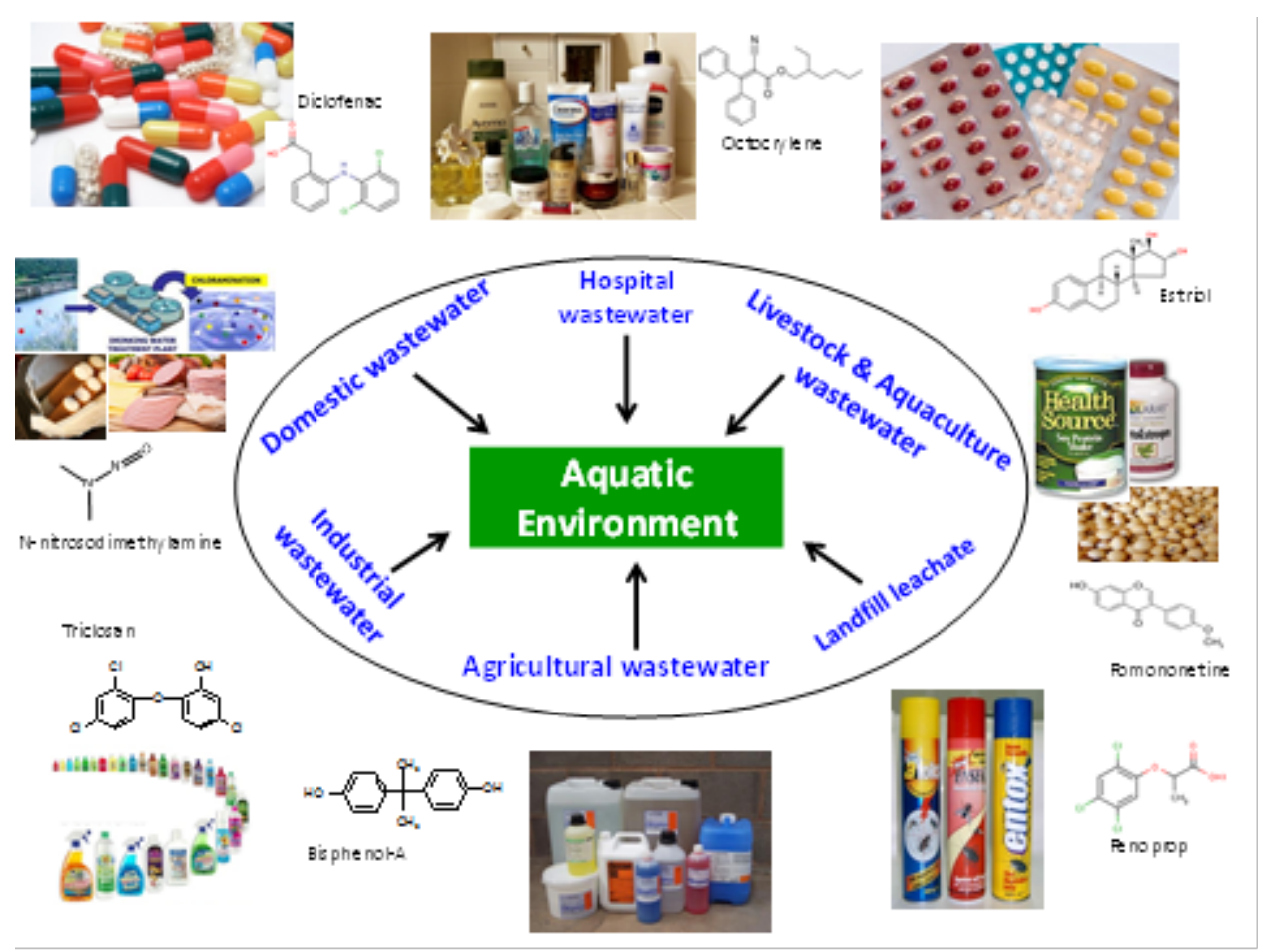

Figure 9.1 


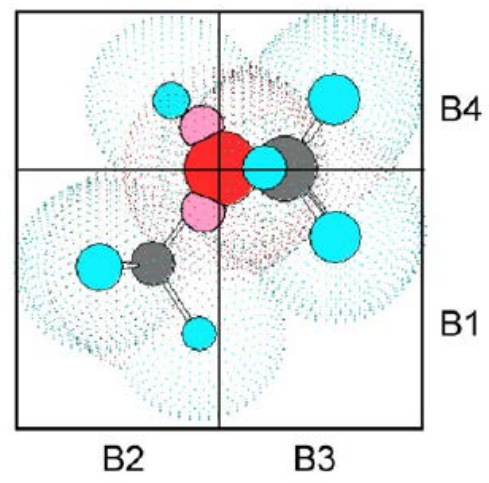

Figure 9.2 


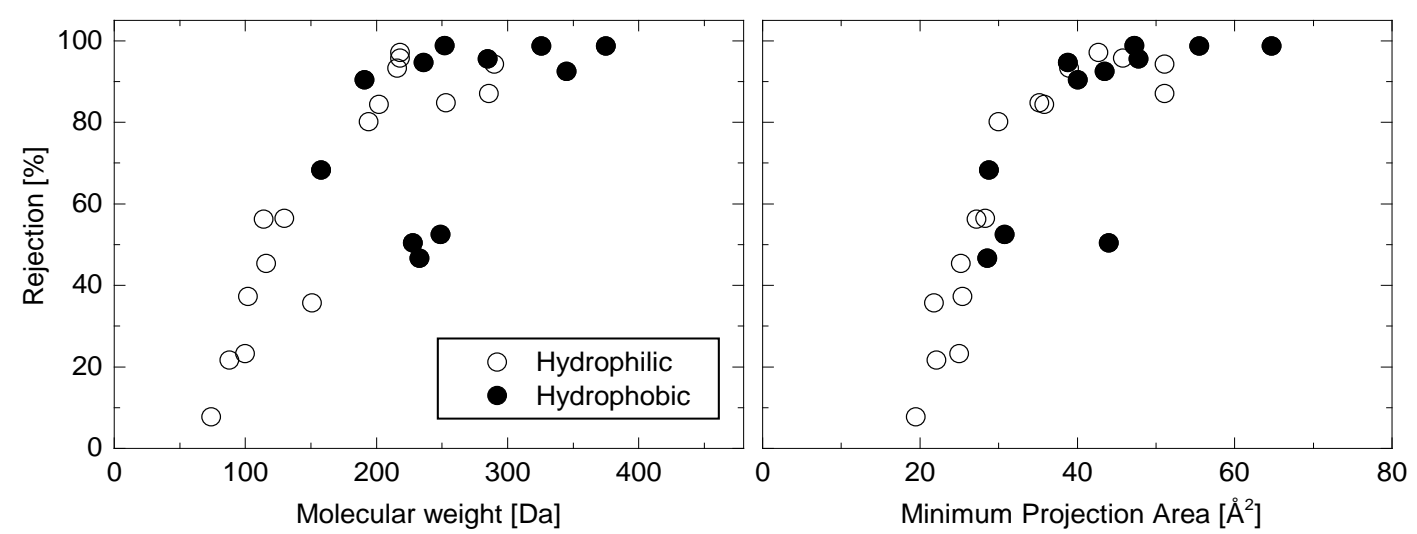

Figure 9.3 

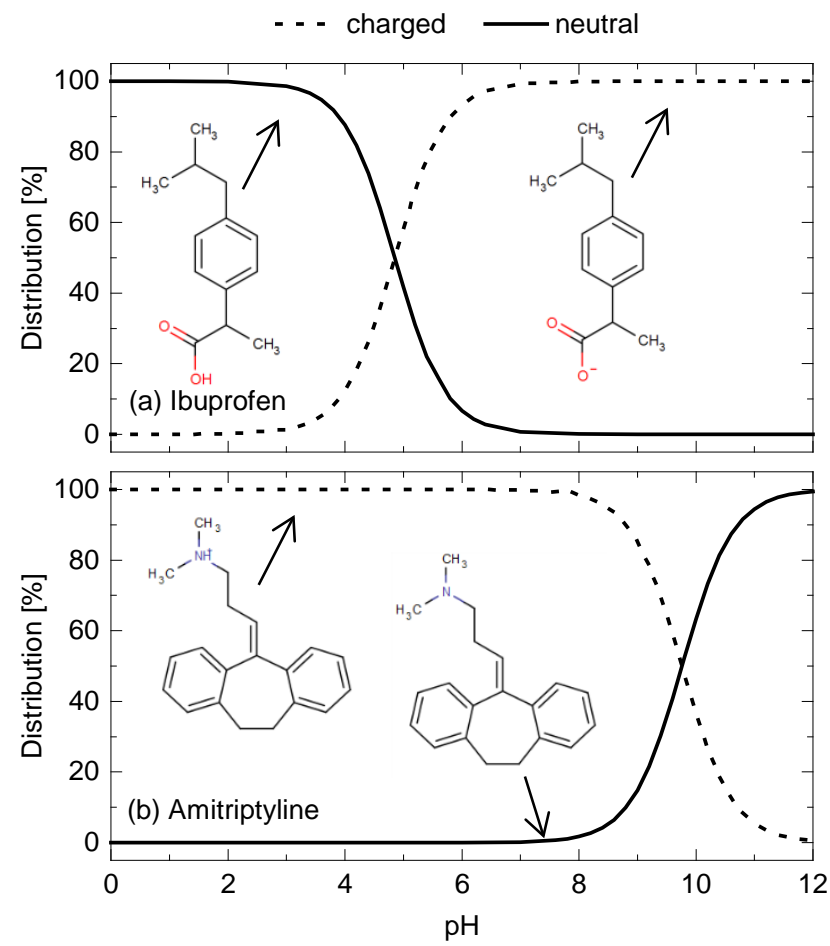

Figure 9.4 


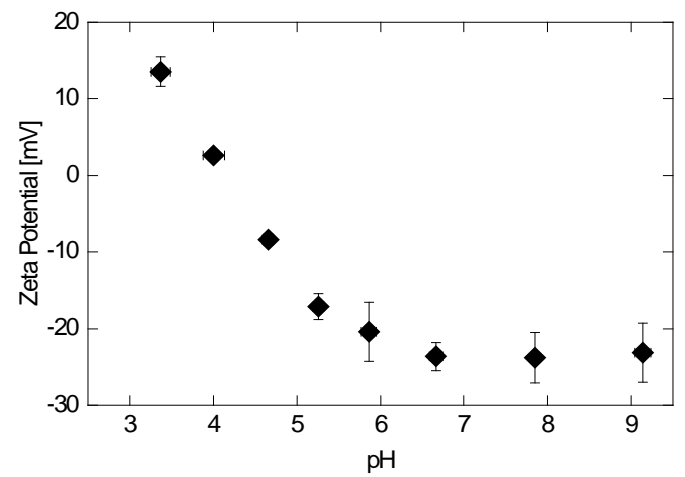

Figure 9.5 


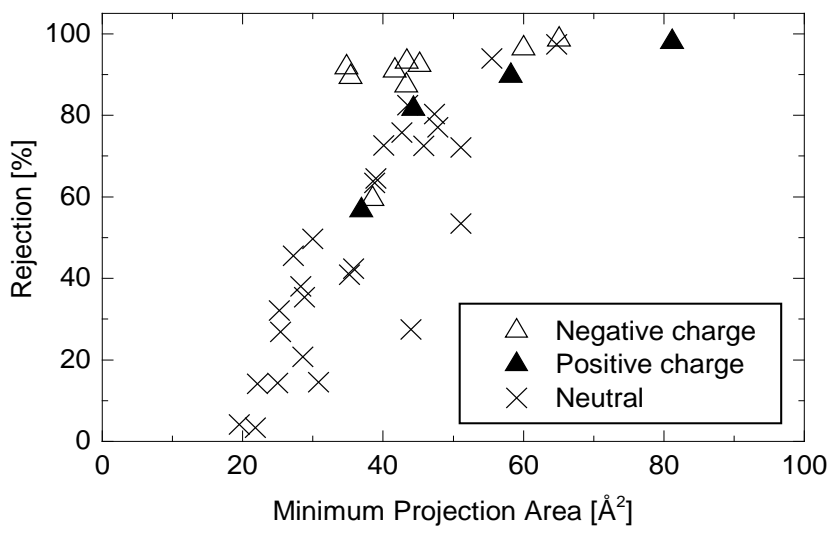

Figure 9.6 


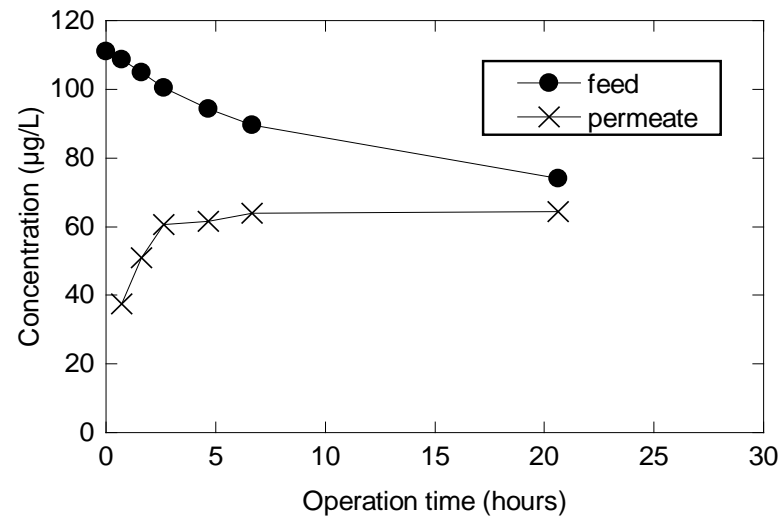

Figure 9.7 

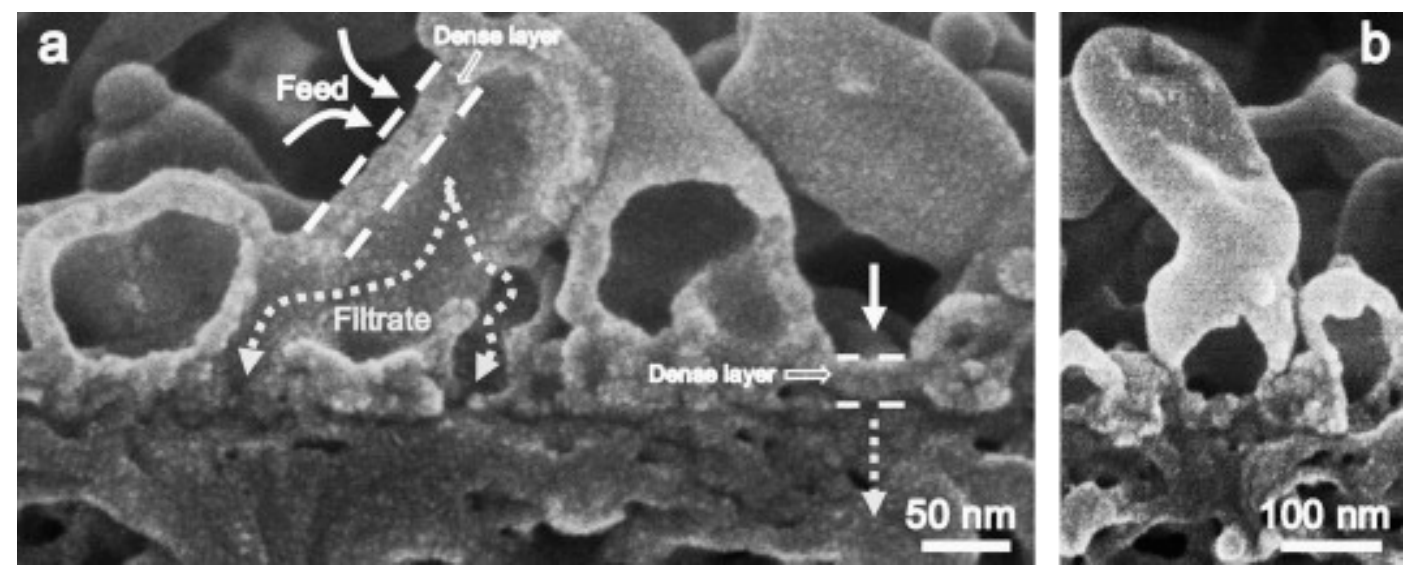

Figure 9.8 


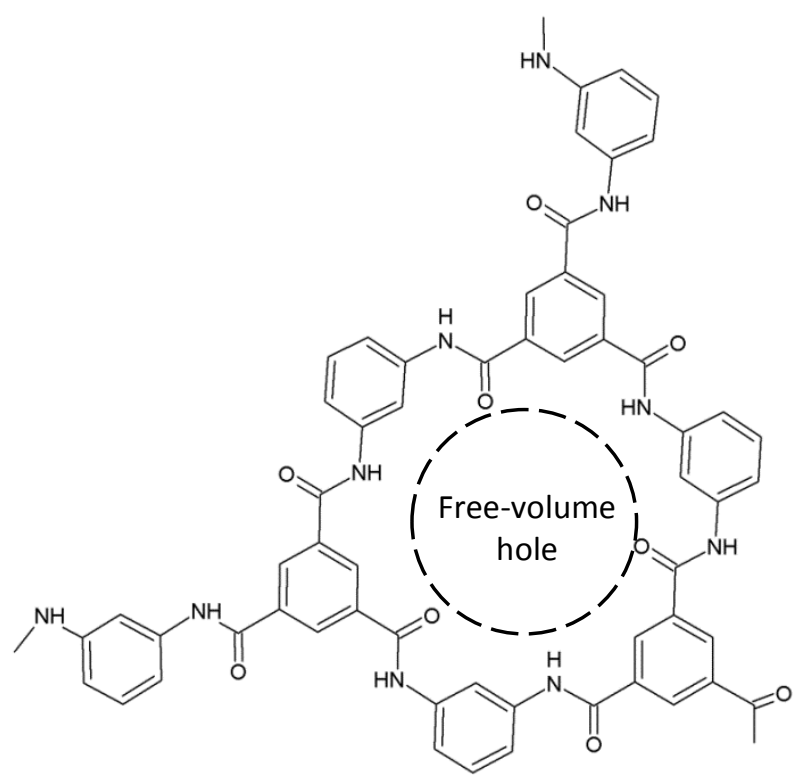

Figure 9.9 


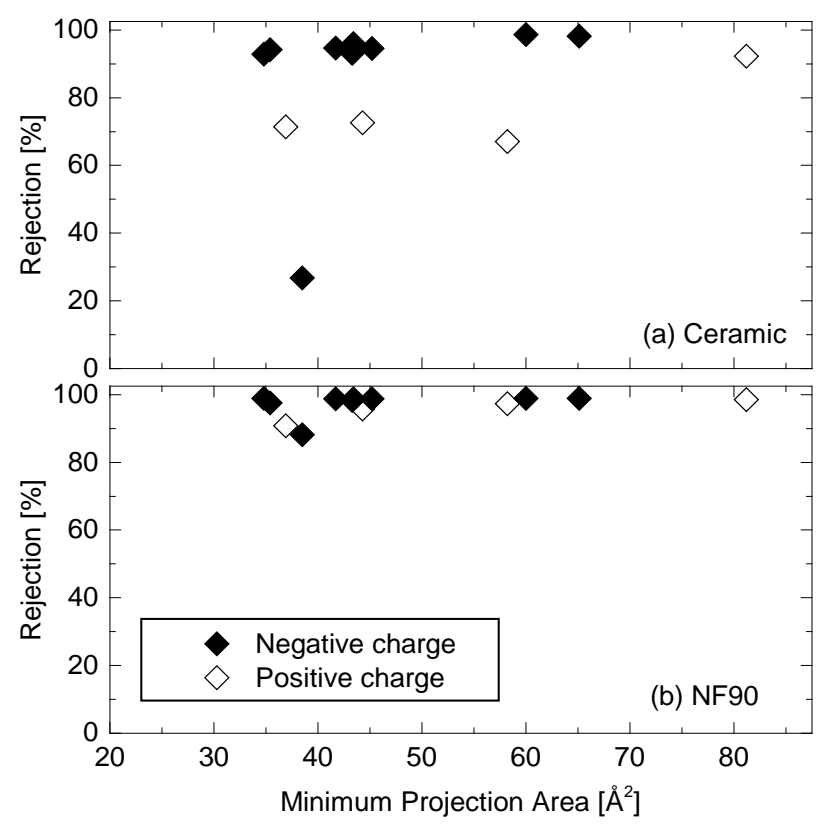

Figure 9.10 


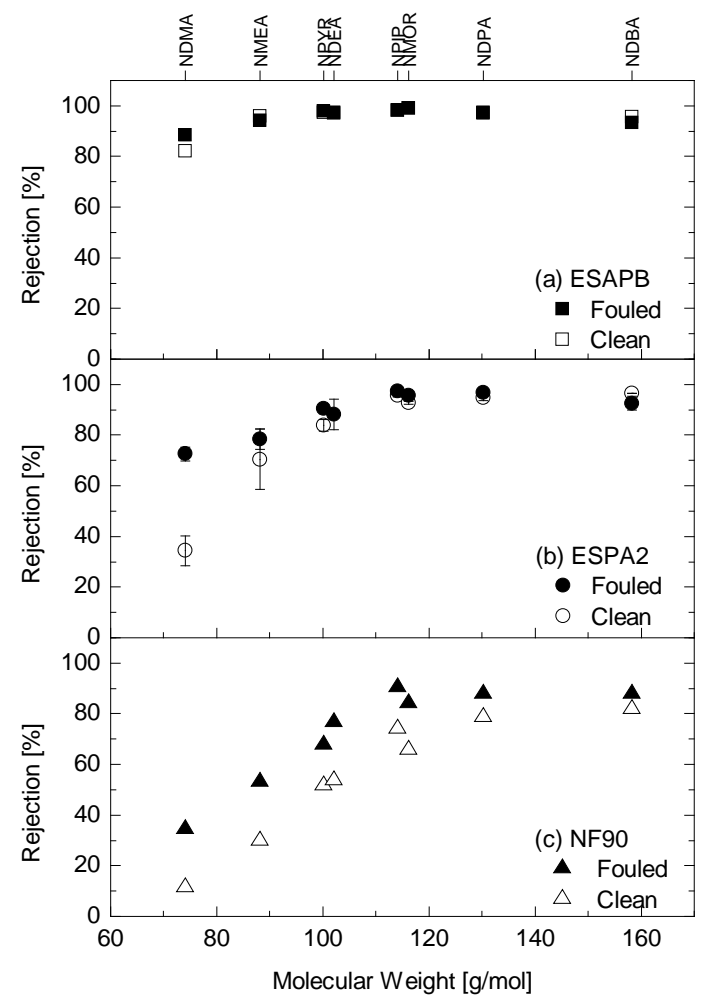

Figure 9.11 


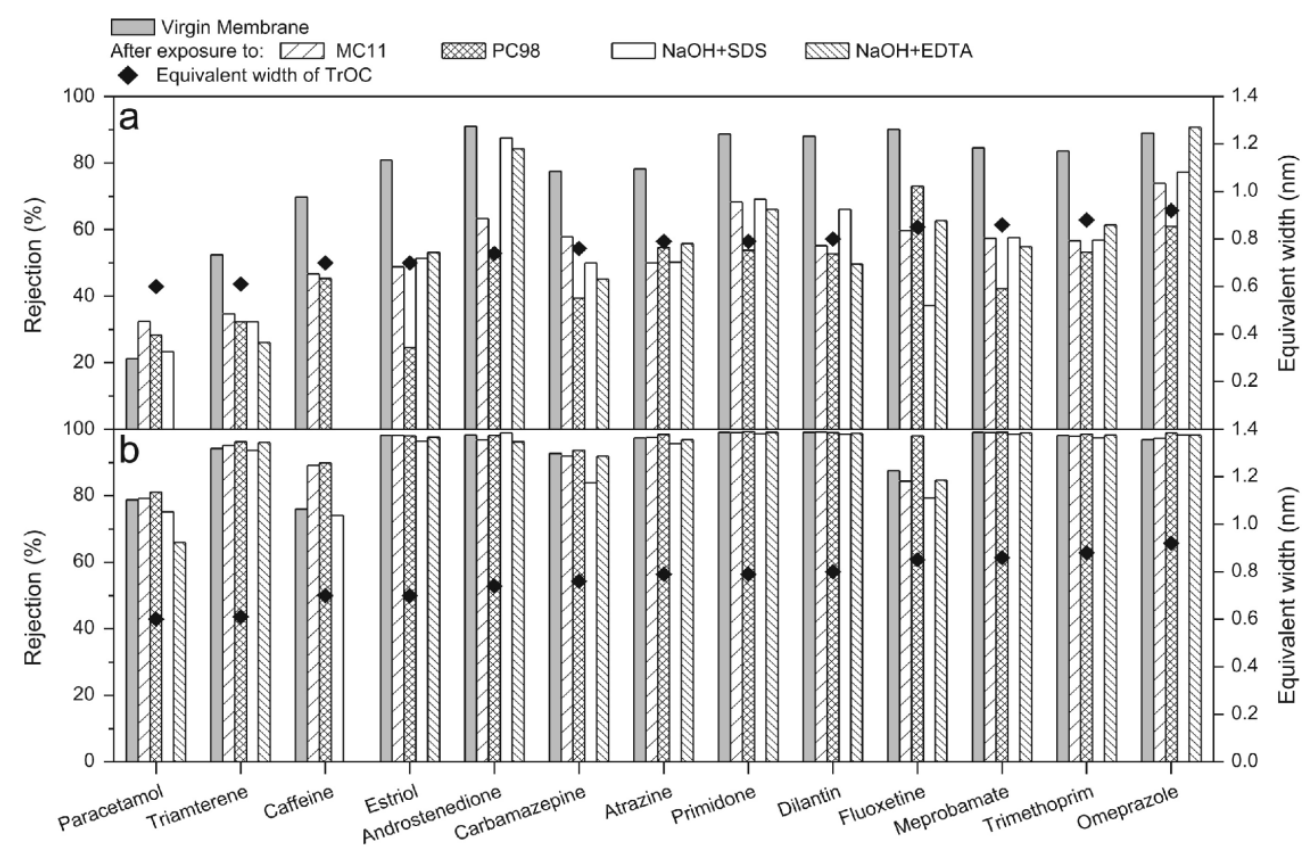

Figure 9.12 

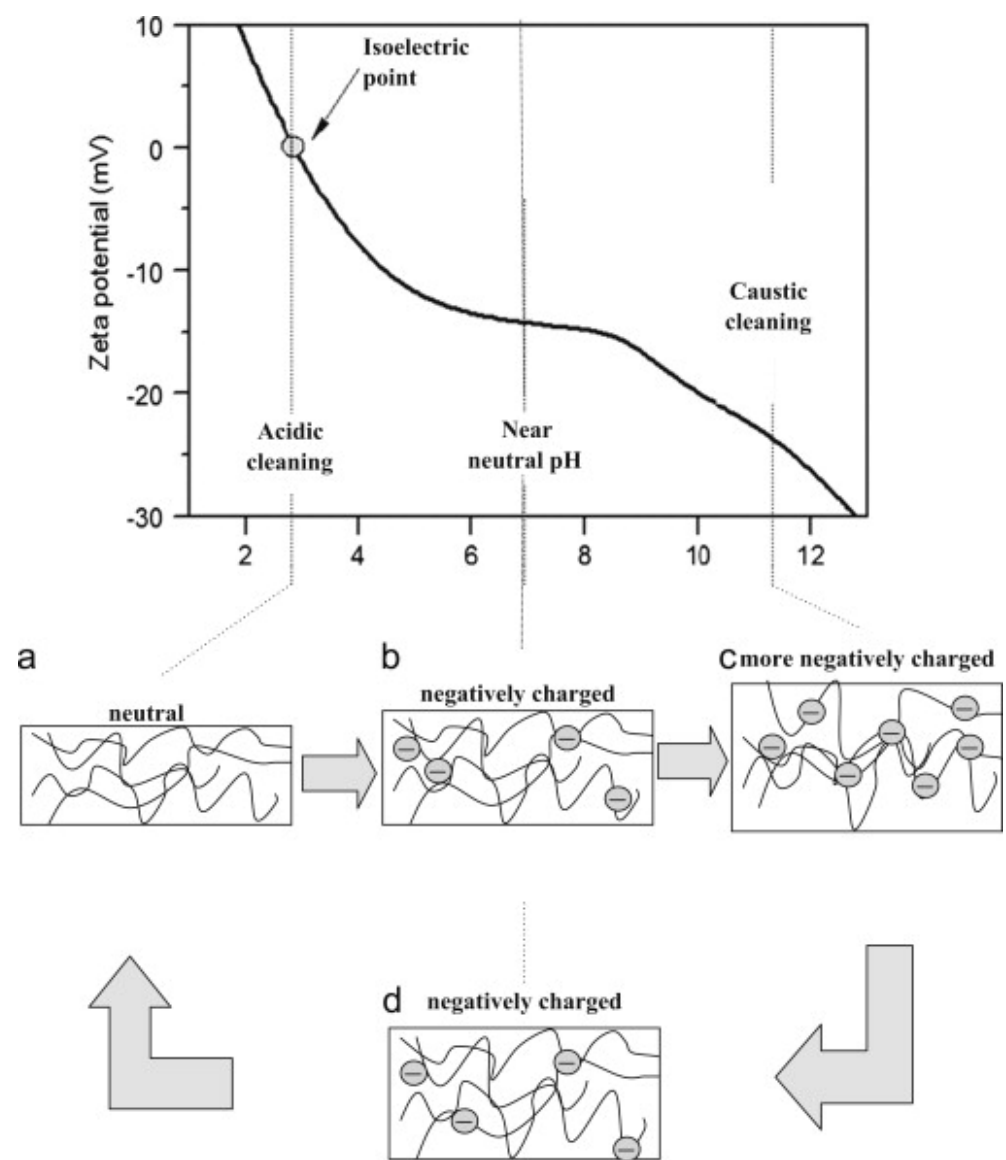

Figure 9.13 


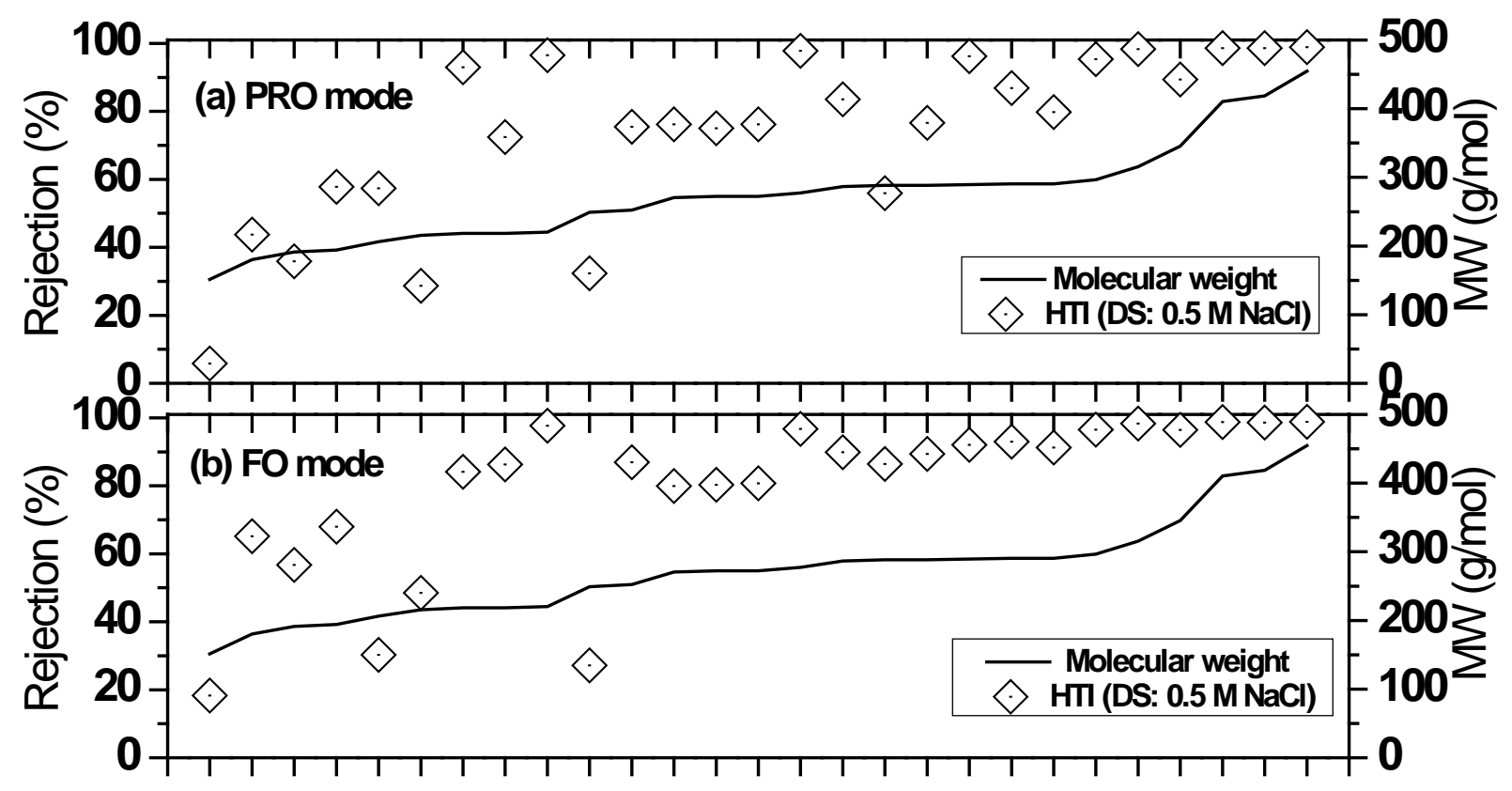

Figure 9.14 


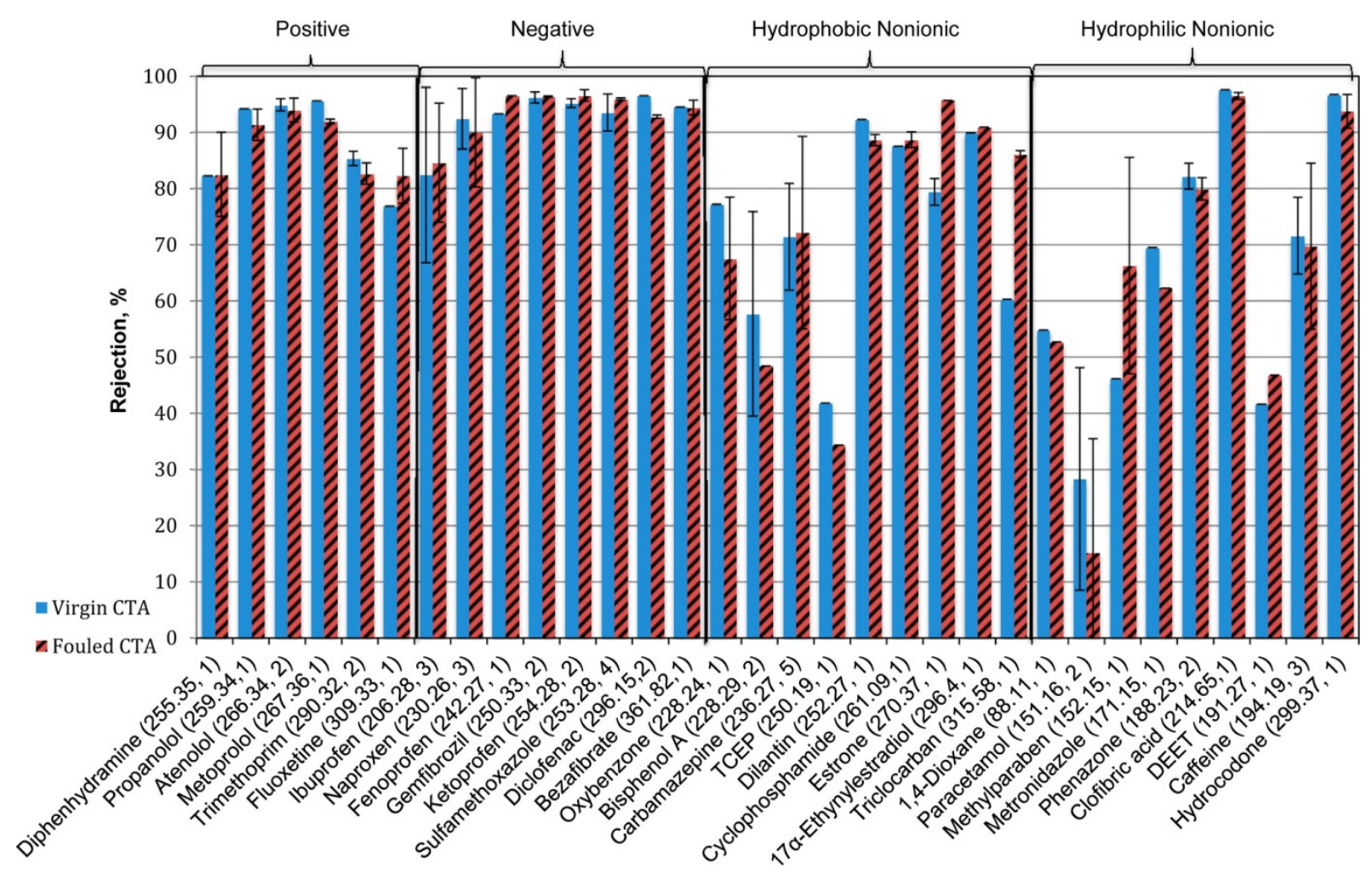

Figure 9.15 


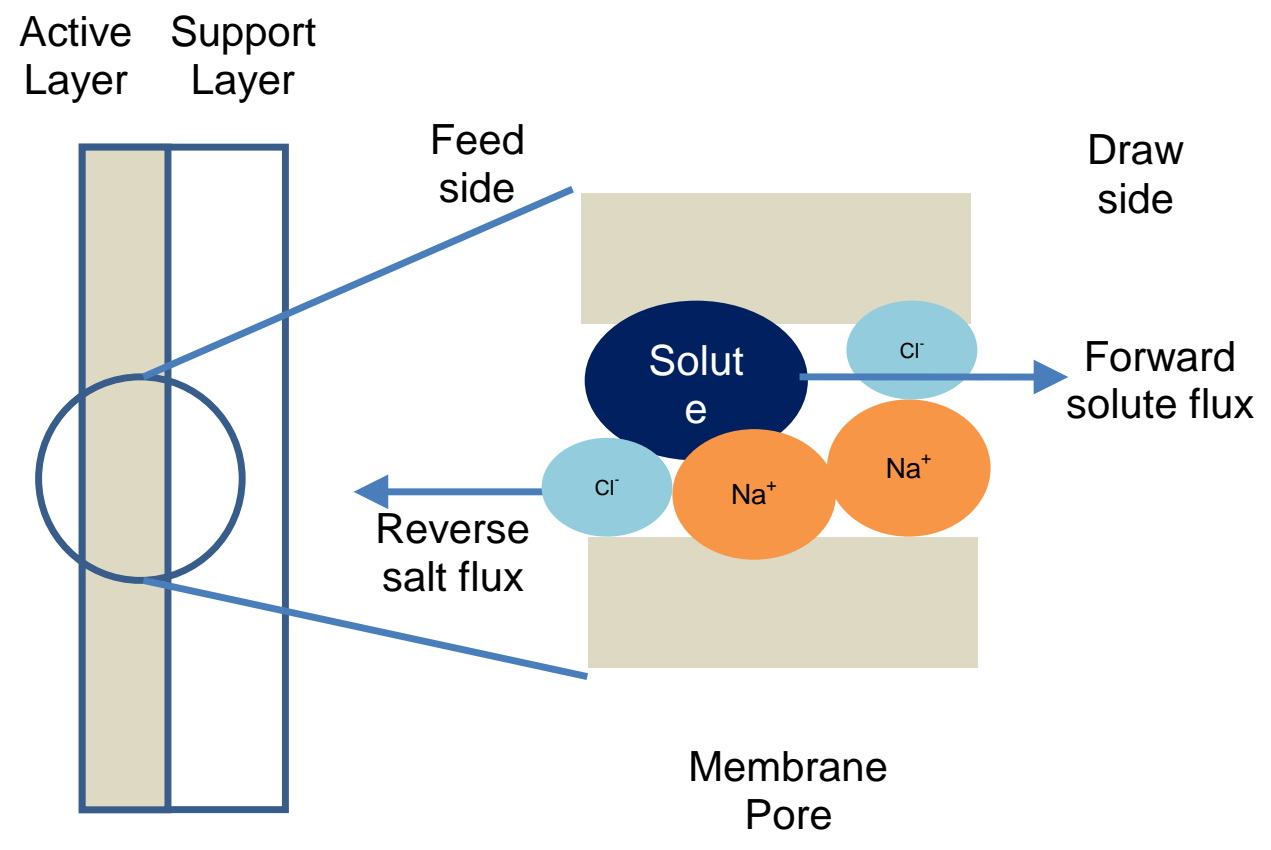

Figure 9.16 


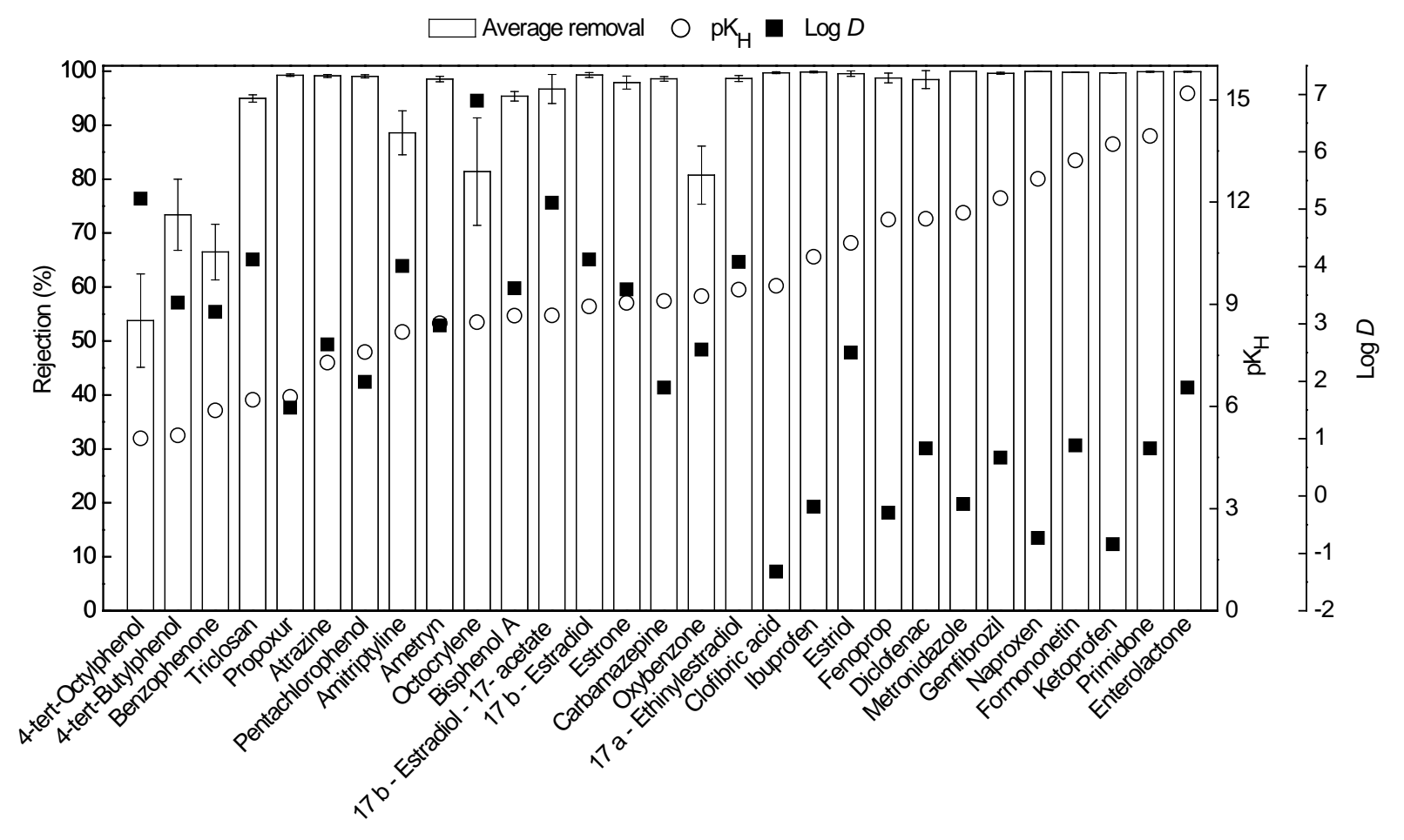

Figure 9.17 


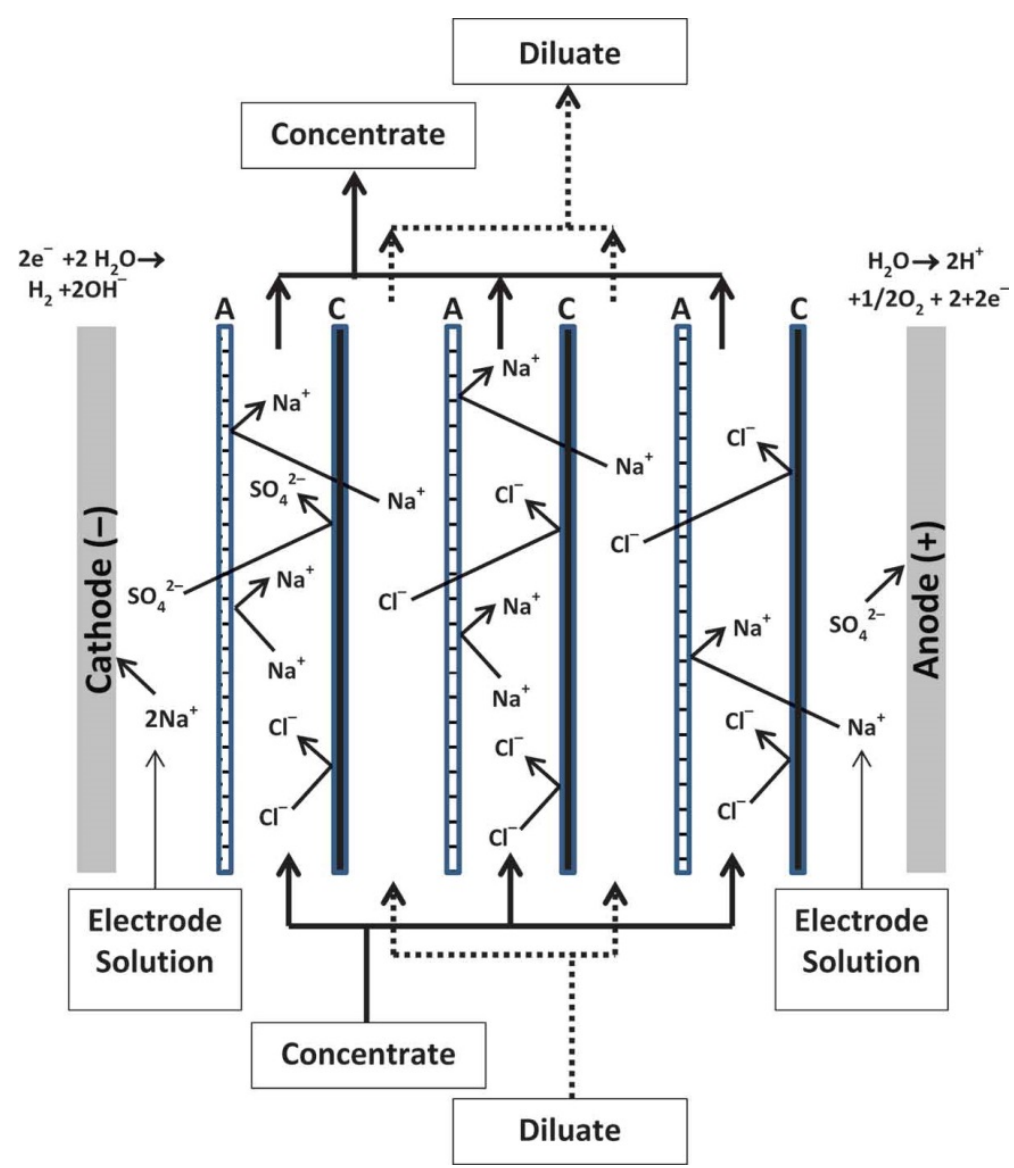

Figure 9.18 